\title{
La cerámica Blanco sobre Rojo en el valle de Chancay y sus relaciones con el estilo Lima
}

Le Blanc sur Rouge dans la vallée de Chancay et ses relations avec le style Lima The White-On-Red pottery sequence in The Chancay Valley And Its Relationship With The Lima Style

Humberto A. Córdova Conza

\section{(2) OpenEdition}

Journals

Edición electrónica

URL: http://journals.openedition.org/bifea/6373

DOI: 10.4000/bifea.6373

ISSN: 2076-5827

Editor

Institut Français d'Études Andines

Edición impresa

Fecha de publicación: 1 abril 2003

Paginación: 69-100

ISSN: 0303-7495

\section{Referencia electrónica}

Humberto A. Córdova Conza, «La cerámica Blanco sobre Rojo en el valle de Chancay y sus relaciones con el estilo Lima », Bulletin de l'Institut français d'études andines [En línea], 32 (1) | 2003, Publicado el 01 abril 2015, consultado el 08 diciembre 2020. URL : http://journals.openedition.org/bifea/6373 ; DOI : https://doi.org/10.4000/bifea.6373

\section{(@) $\odot \Theta$}

Les contenus du Bulletin de l'Institut français d'études andines sont mis à disposition selon les termes de la licence Creative Commons Attribution - Pas d'Utilisation Commerciale - Pas de Modification 4.0 International. 
Bull. Inst. fr. études andines

2003, 32 (1): 69-100

\title{
LA CERÁMICA BLANCO SOBRE ROJO EN EL VALLE DE CHANCAY Y SUS RELACIONES CON EL ESTILO LIMA
}

\author{
Humberto A. CÓRDOVA CONZA*
}

\section{Resumen}

En el presente artículo exponemos los resultados de las investigaciones arqueológicas en Baños de Boza, valle de Chancay, realizadas en 1997. Este es uno de los pocos sitios conocidos con arquitectura monumental pública asignada a las fases iniciales del Período Intermedio Temprano y relacionada con la tradición cerámica Blanco sobre Rojo.

Nuestro interés principal fue refinar la cronología del Blanco sobre Rojo en el valle bajo de Chancay mediante información estratigráfica y compararla con otros esquemas cronológicos para la costa central. Como resultado, definimos una secuencia arquitectónica de seis fases que implicaban cambios funcionales. Las tres primeras fases son de uso doméstico, con alto contenido de restos culturales. Las fases siguientes se caracterizan por la construcción de grandes muros para plataformas hechos de adobe plano-convexo. Respecto a la cerámica, tenemos una secuencia de cuatro fases netamente Blanco sobre Rojo, que guardan íntima relación con el desarrollo arquitectónico. Esta cronología puede ser correlacionada con la de Miramar, propuesta por Patterson (1961-1966).

Finalmente, otro aspecto interesante era el momento de transición entre Blanco sobre Rojo y Lima. Considerando que las evidencias de ocupación Lima en Baños de Boza son escasas, revisamos la información estratigráfica de Cerro Trinidad y Playa Grande. De esta manera, observando las claras diferencias entre el Blanco sobre Rojo y Lima, suponemos que, al menos en el valle de Chancay, Lima no deriva estilísticamente del Blanco sobre Rojo sino que es un elemento foráneo. Además, ambos estilos coexisten durante un cierto período.

Palabras claves: Blanco sobre Rojo, Período Intermedio Temprano, horizonte, estratigrafía, seriación, adobe plano-convexo, mamiforme, estilo Lumbra.

\section{LE BLANC SUR ROUGE DANS LA VALLÉE DE CHANCAY ET SES RELATIONS AVEC LE STYLE LIMA}

\section{Résumé}

Nous exposons dans cet article les résultats des investigations arqueológiques des Bains de Boza dans la vallée de Chancay, réalisées en 1997. C'est un des rares endroits connus où l'on trouve une architecture monumentale publique consacrée aux phases iniciales de la Période Intermédiaire Ancien, avec une tradition céramique Blanc sur Rouge.

*Av.Los Héroes 881, San Juan de Miraflores, Lima, Perú. E-mail: humbertc24@ latinmail.com. 
Notre principal interêt a été d'affiner la chronologie du Blanc sur Rouge dans la vallée basse de Chancay au moyen d'information stratigrafique et de la comparer avec d'autres schémas chronologiques pour la côte centrale. Le résultat se définit en une séquence architectonique de six phases impliquant des changements fonctionnels. Les trois premières phases sont d'usage domestique avec un haut contenu de résidus culturels. Les phases suivantes se caractérisent par la construction de grands murs soutenants des plateformes faites de briques de terre plates et convexes. En ce qui concerne la céramique, on a une séquence de quatre phases nettement Blanc sur Rouge, liées au développement architectonique. Cette séquence peut être comparée avec celle de Miramar, proposée par Patterson (1961-1966).

Finalement, un autre aspect intéressant fut le moment de transition entre Blanc sur Rouge et Lima. Si l'on considère que les évidences d'occupation Lima dans les Bains de Boza sont rares, il est nécessaire de revoir l'information stratigraphique de Cerro Trinidad et Playa Grande. De cette façon, en observant les différences nettes entre le Blanc sur Rouge et Lima, on suppose, qu'au moins dans la vallée de Chancay, Lima ne vient pas du style du Blanc sur Rouge, mais que c'est plutôt un élément étranger. De plus, les deux styles coexistent durant une certaine période.

Mots clés : Blanc sur Rouge, Période Intermédiaire Ancien, horizon, stratigraphie, sériation, brique de terre plate-convexe, mamelliforme, style Lumbra.

\title{
THE WHITE-ON-RED POTTERY SEQUENCE IN THE CHANCAY VALLEY AND ITS RELATIONSHIP WITH THE LIMA STYLE
}

\begin{abstract}
In the present article, we present the results of the archaeological investigations at Baños de Boza, Chancay Valley, made in 1997. This one of the few known sites with public monumental architecture ascribed to the initial phases of Early Intermediate Period that are characterized by the White-on-Red pottery tradition.

Our main interest was to investigate the White-on-Red chronology in the lower Chancay valley through stratigraphic information and to compare the resulting sequence with other chronological schemes from Peru's central coast. As a result of the research, we define a six phase architectural sequence which indicate functional changes at he site. The three first phases reflect domestic use of the site with a high volume of cultural remains. The following phases are caracterized by the building of large plataform walls made of plain-convex adobe. In terms of the pottery, we have developed a four phase sequence for the White-on-Red style, which correlates with the Mirimar phase proposed by Patterson (1961-1966), and is closely related to the architectural developments at he site.

Finally, another interesting theme was the transicional period between the White-on-Red and Lima cultures. Considering that the slight evidence of Lima ocupation at Baños de Boza, we review the stratigraphic information from Cerro Trinidad and Playa Grande. By observing the obvious differences among White-on-Red and Lima styles, we presume that Lima doesn't derive stylistically from White-on-Red in the Chancay Valley but rather that it is a foreign element introduced from the outside. Moreover, the two styles coexist for a period of time.
\end{abstract}

Key words: White-on-Red, Early Intermediate Period, horizon, stratigraphy, seriation, plainconvex adobe, mamiform, Lumbra style.

\section{INTRODUCCIÓN}

El Período Intermedio Temprano es una época de grandes cambios culturales tanto en lo político, tecnológico, como artístico. Dentro de este contexto observamos la formación de sociedades altamente desarrolladas, así como la aparición de nuevos y 
variados estilos cerámicos. Este período, también, a la luz de las recientes investigaciones, resulta ser más complejo y, a la fecha, se observan algunos vacíos en la información que merecen ser complementados. En esta discusión queremos tratar, de manera especial, la primera parte del Período Intermedio Temprano, época en que se desarrolla la tradición Blanco sobre Rojo; a la vez abordaremos las relaciones con el posterior estilo Lima.

La información que se maneja a la fecha sobre el Blanco sobre Rojo es bastante clara, principalmente gracias a los trabajos pioneros de Max Uhle en 1904 (Kroeber, 1926) y Gordon Willey en 1943, quienes caracterizaron esta tradición en el valle de Chancay. Sin embargo, la información de Willey presenta ciertas limitaciones como resultados de la metodología empleada: el uso de niveles arbitrarios de hasta $50 \mathrm{~cm}$ en deposiciones culturales bien diferenciadas que incluían pisos, así como el uso de una tipología basada íntegramente en decoración. Además, de los siete pozos excavados en Cerro Trinidad, sólo cuatro, IV-VII y V-VI, muestran una correlación estratigráfica por ser adyacentes, lo cual afecta también la definición de relaciones cronológicas entre contextos funerarios.

No obstante, la información estratigráfica de Willey en Cerro Trinidad es bastante útil para cruzar los datos de cerámica y arquitectura. Básicamente, existen tres grandes momentos, según los pozos de excavación IV-VII, a saber, una fase netamente Blanco sobre Rojo desde los niveles más profundos ( 8 al 11) hasta el piso G. Luego viene una etapa intermedia donde coexisten el Blanco sobre Rojo e Interlocking, entre el piso G y el E. Finalmente, tenemos una ocupación Interlocking desde el piso E hasta los niveles superiores. Un aspecto interesante es esta etapa transicional, donde coexisten ambos estilos; una situación similar se aprecia en el pozo V donde tanto el Blanco sobre Rojo como Interlocking tienen una presencia continua.

Willey, si bien caracterizó a Baños de Boza como un sitio netamente Blanco sobre Rojo, no consideró la información estratigráfica de este para correlacionarlo con Cerro Trinidad pues sostenía que no se producían variaciones entre tipos. Ello es comprensible si consideramos, según las descripciones de Willey, que tres de los cuatro pozos que excavó (I, II y III) se ubicaban en zonas periféricas del sitio donde, como observamos en nuestros recientes trabajos, las evidencias de actividad humana son escasas. Los datos de Baños de Boza, no obstante, sirvieron para complementar su tipología y caracterizar los elementos constructivos asociados. Además, un dato importante es que define el sitio como una plataforma con fines religiosos, asociado a pequeños cuartos tipo celda (Willey, 1943: 188).

La necesidad de una periodificación más fina fue solucionada en gran parte con los trabajos de Patterson (1961-1966) quien, basándose en la cronología de Rowe de Horizontes y Períodos, propuso una secuencia de cuatro fases para el Blanco sobre Rojo de Ancón, denominado estilo Miramar, y nueve para el estilo Lima. El esquema propuesto por Patterson pronto se convertiría en una secuencia maestra para la costa central, mediante la cual se podía fechar hallazgos desde el valle de Huaura hasta Lurín. Este esquema mantiene su vigencia hasta hoy, aunque, a la luz de estudios recientes, viene siendo cuestionada.

En décadas posteriores, las investigaciones revelaron que el Blanco sobre Rojo se manifestaba en una clara diversidad estilística a lo largo de la costa central y 
muchas de estas colecciones alfareras dejaban ver diferencias con Miramar. Así, en el valle de Lurín observamos un predominio de decoración Rojo sobre Blanco y botellas escultóricas zoomorfas, como lo demuestran las colecciones de Villa el Salvador (Stothert \& Ravines, [1977]) y Tablada de Lurín (Cárdenas, 1999); mientras que en Végueta, valle de Huaura, son frecuentes los cántaros y tinajas (Shady \& Ruíz, 1979). Estos especímenes corresponden al Período Intermedio Temprano, contemporáneos con Miramar, pero por sus diferencias, difícilmente pueden ser ubicados en algunas de sus fases.

Quizás el concepto de "Horizonte Tecnológico Blanco sobre Rojo", enunciado por Willey (1953), contribuyó a que durante mucho tiempo se entendiera el Blanco sobre Rojo como un fenómeno homogéneo en el área andina. Una serie de rasgos estilísticos recurrentes vino a reforzar esta idea, como es la pintura blanca, ollas con cuello corto y la cocción oxidante. Un ejemplo de esta tendencia son los trabajos de Ernesto Tabío quien, en un primer momento denominó como estilo Baños de Boza al Blanco sobre Rojo de Ancón. Poco después, gracias a los datos que le proporcionará Edward P. Lanning, Tabío bautizó este estilo como Miramar (Tabío, 1965: 76-77).

La cronología propuesta por Patterson tiene otra particularidad pues fue elaborada principalmente en base a seriación de rasgos, con cierta información de excavación que le permitió fechar mejor algunos elementos, principalmente de Lima. La cronología en Miramar se elaboró similarmente pues Base aérea y Tricolor fueron ubicados sobre niveles del Horizonte Temprano (Patterson, 1961-1966: 7). Base Aérea era un grupo cerámico netamente Blanco sobre Rojo mientras que Tricolor se orientaba más hacia Lima. Esta diferencia hizo suponer a Patterson la existencia de un lapso de tiempo entre ambos, el cual fue completado con las fases Urbanización y Polvorín, mediante una seriación.

Dadas estas condiciones creemos que sería infructuoso aplicar una sola secuencia en áreas estilísticamente distintas. Más aún, es necesario incidir en los elementos propios de cada región y plantear secuencias locales tomando como base el dato estratigráfico. Bajo este criterio decidimos estudiar una de las manifestaciones regionales del Blanco sobre Rojo, que se da en el valle de Chancay, específicamente en el sitio de Baños de Boza. Los principales objetivos, fueron definir la cronología y la función del sitio.

\section{UBICACIÓN Y DESCRIPCIÓN DEL ÁREA}

El área de Baños de Boza se ubica en la parte baja del valle de Chancay (Fig. 1). Es un terreno fértil dedicado principalmente a la agricultura y ganadería, pero, adyacente a un territorio desértico al este y sur. Este área también se caracteriza por presentar algunas áreas pantanosas que permiten sostener una abundante vegetación de juncos. Ciertamente, las lagunas y pantanos proporcionaban caña, junco y totora, fibras útiles para la construcción de viviendas, techos, etc. Rostworowski (1981), citando a Maldonado (1943), caracteriza las lagunas como de un tipo estancado, donde prolifera el carbonato y bicarbonato de sodio, el cual permite el desarrollo de las algas Arthrospira Platensis, más no así, la vida de peces y moluscos. Dichos vegetales eran explotados en épocas prehispánicas y los inicios de la colonia por poblaciones dedicadas al cultivo de la totora. Actualmente, mucha de esta antigua flora y fauna ha desaparecido para dar paso a la agricultura, como nos lo explicaron los mismos pobladores. 


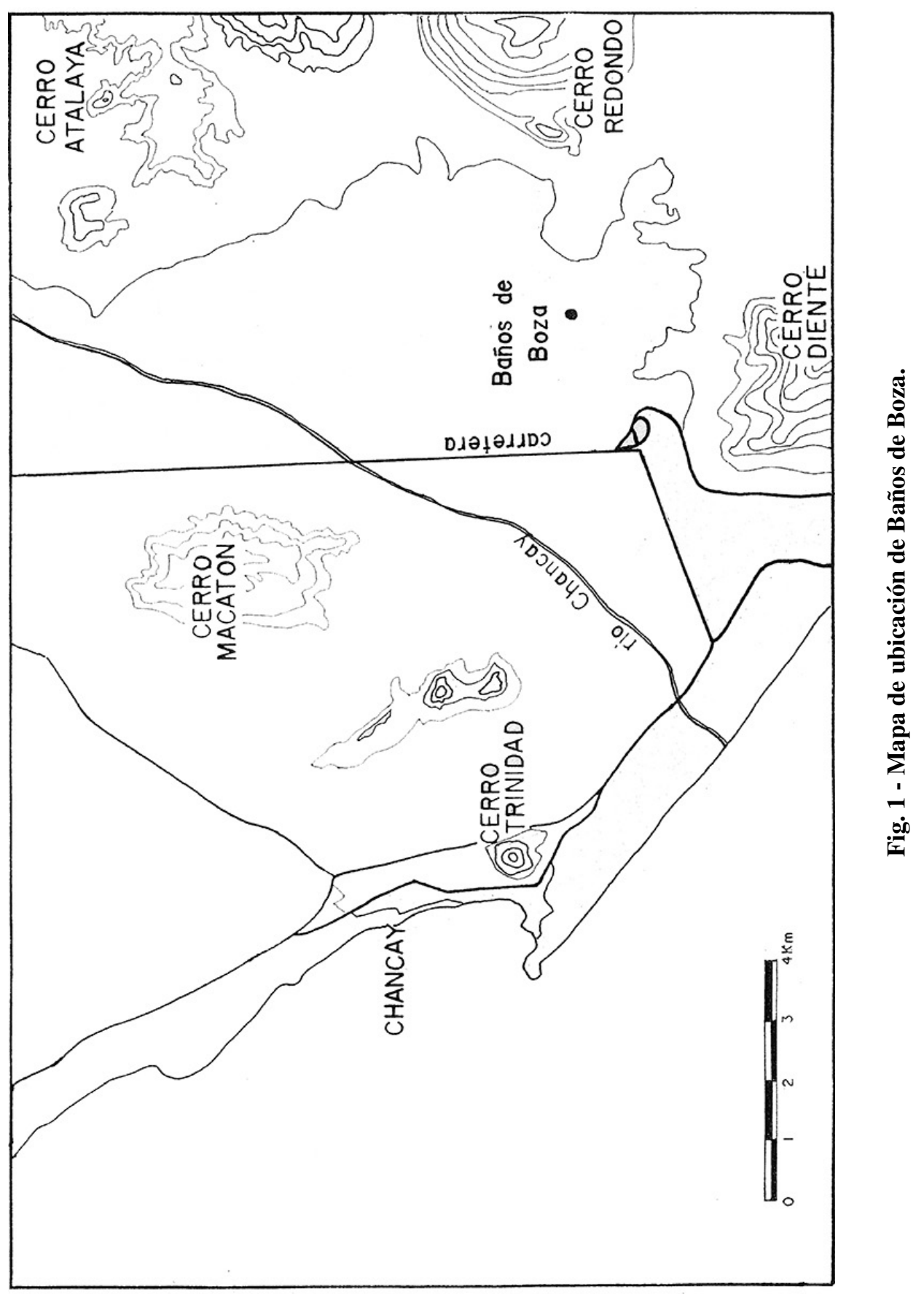


La denominación "Baños" proviene del uso profiláctico que se le daba a los afloramientos de agua salitrosa del lugar. Esta característica condiciona el patrón ocupacional del área dado que la fuerte salitrocidad del terreno impide la conservación de construcciones a menos que estas se realicen sobre montículos. Algunos de estos montículos corresponden a pequeñas dunas de baja altitud que sobresalen entre el verde campo. Otros, en cambio, son sitios arqueológicos, como el caso de Baños de Boza.

Durante nuestros recorridos por el área observamos varios otros sitios arqueológicos, algunos intactos y otros destruidos, de los cuales sólo quedaban fragmentos de cerámica en los surcos de las chacras. De los sitios visitados, destaca uno catalogado como 3JO4 (Agurto \& Sandoval, 1974) (Fig. 2 A). Su arquitectura tiene una apariencia aterrazada y adopta forma cuadrangular. Los muros exteriores fueron construidos en piedra canteada y unidos con argamasa, mientras que en algunos lugares donde son visibles, los muros internos están enlucidos. Este sitio se halla adyacente a un área de enterramiento muy disturbada por el huaqueo y en donde puede observarse cerámica Blanco sobre Rojo, Lima, Nievería y Chancay.

Otro sitio arqueológico que resalta por sus grandes dimensiones es uno que se ubica a $400 \mathrm{~m}$ de Baños de Boza al cual hemos denominado simplemente como sitio 2 (Fig. 2 B). Esta es, también, una estructura cuadrangular de unos $80 \mathrm{~m}$ de largo, 20 de ancho y 10 alto, aproximadamente. Se halla mayormente cubierto por arena, pero se puede observar algunos muros de piedra canteada en su flanco norte. En la cima, se puede observar cabezas de muros rectos hechos en piedra y barro y enlucidos. La cerámica es predominantemente Blanco sobre Rojo y sólo se halló un fragmento Lima.

\section{ARQUITECTURA DE BAÑOS DE BOZA}

La arquitectura pública relativa a la tradición Blanco sobre Rojo en la costa central ha sido investigada de manera muy escueta, pues se ha dado mayor interés a los sitios monumentales Lima. Los datos proceden mayormente de estudios generales sobre patrón de asentamiento como el que realiza Patterson en Ancón y en el valle bajo del Chillón mencionando algunas plataformas asociadas a aldeas dispersas correspondientes a inicios del Período Intermedio Temprano. Una de estas plataformas se conoce como Huaca Santa Rosa (PV46-48 según Patterson, 1966: 107). También tenemos estudios en lugares específicos como los ya mencionados Cerro Trinidad (Willey, 1943) y Villa el Salvador (Stothert \& Ravines, [1977]), cuyas afinidades con Baños de Boza resultan muy interesantes. En ellos encontramos un elemento recurrente como es el adobe plano convexo que se asocia cronológicamente a cerámica Blanco sobre Rojo y a los inicios de Lima.

Nuestras investigaciones en Baños de Boza revelaron nuevas evidencias sobre la arquitectura de este período. La limpieza de un extenso perfil en el flanco oeste del sitio (Fig. 3), producto de su destrucción parcial en la década del 80 y la nueva excavación del pozo IV que realizara Willey en 1941, mostró sus principales características arquitectónicas, una de las cuales es la presencia de adobes plano convexos hechos a mano. Los muros están construidos mediante dos caras de adobes y un relleno intermedio compuesto de barro suelto y adobes fragmentados. La calidad de estos adobes guarda relación con el tamaño de los muros pues aquellos de menores 


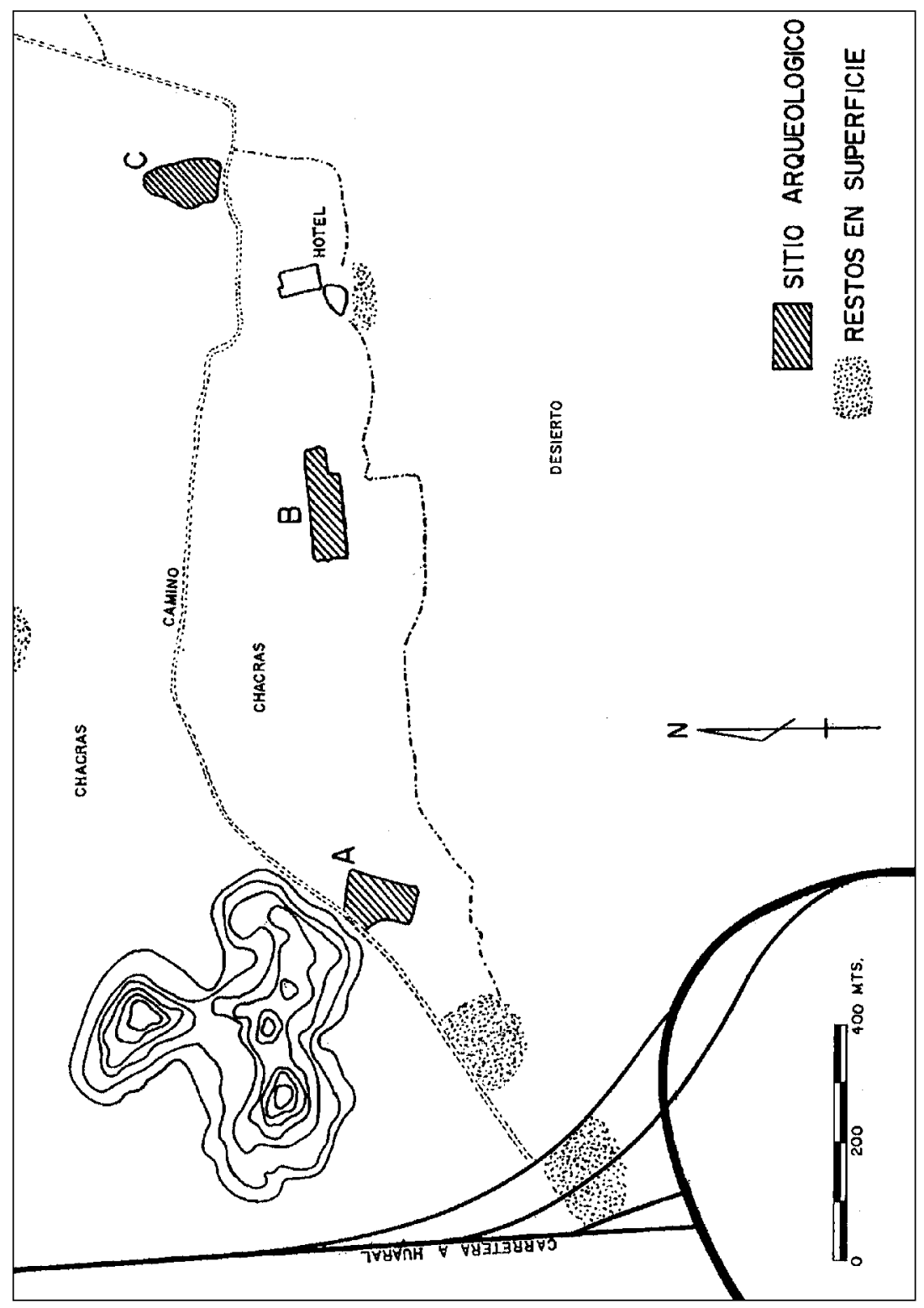

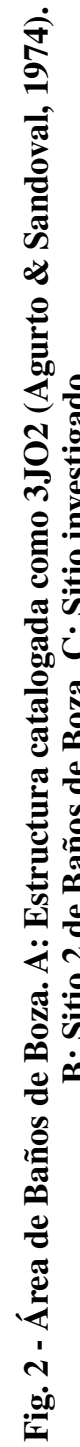




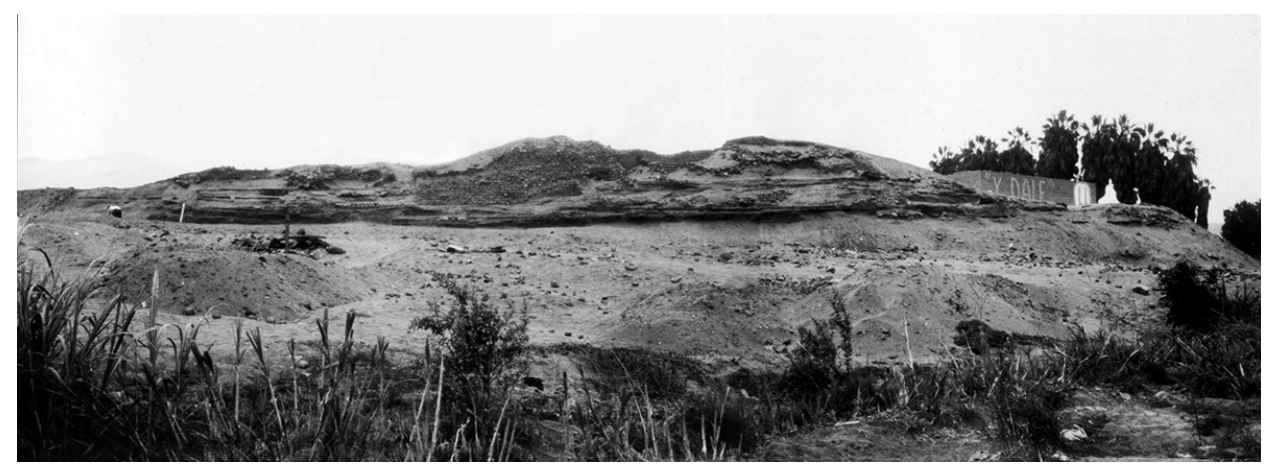

Fig. 3 - Vista del perfil mayor en el flanco oeste del sitio.

dimensiones están hechos de adobes amorfos y pequeños, mientras que en las paredes altas se usan adobes mejor acabados. También se utiliza la piedra pero su uso se restringe a cimientos y en algunos muros bajos en los niveles superiores. Todos los muros se asientan directamente sobre pisos de barro, sin penetrar en ellos. Estos pisos, a su vez, para lograr la estabilidad necesaria, se sustentan en rellenos de barro suelto mezclados con fragmentos de adobe y piedras. Todo el edificio ha sido construido sobre una duna natural, previamente aplanada.

En Baños de Boza definimos hasta seis fases constructivas separadas claramente por pisos de barro (Fig. 4). La primera fase comprende desde las capas más profundas, sin arquitectura, hasta el piso 10; luego de lo cual prosigue la fase 2 , hasta el piso 9-12. la tercera fase se ubica entre los pisos 9-12 y 8-11. Estas tres etapas tempranas muestran algunas características en común, como pisos delgados sobre rellenos de barro sueltos y muros bajos de manufactura tosca, tales como 15, 18, 19 y 20. Esta arquitectura se asocia a capas de material orgánico y ceniza con abundante material cultural, depositada directamente sobre los pisos y entre los muros, lo cual evidencia una actividad doméstica intensa.

A partir de la fase 4 (desde el piso 8-11) se inicia la tradición de construir cuartos de relleno para la conformación de plataformas mediante muros altos (Figs. 5, 6, A y B).

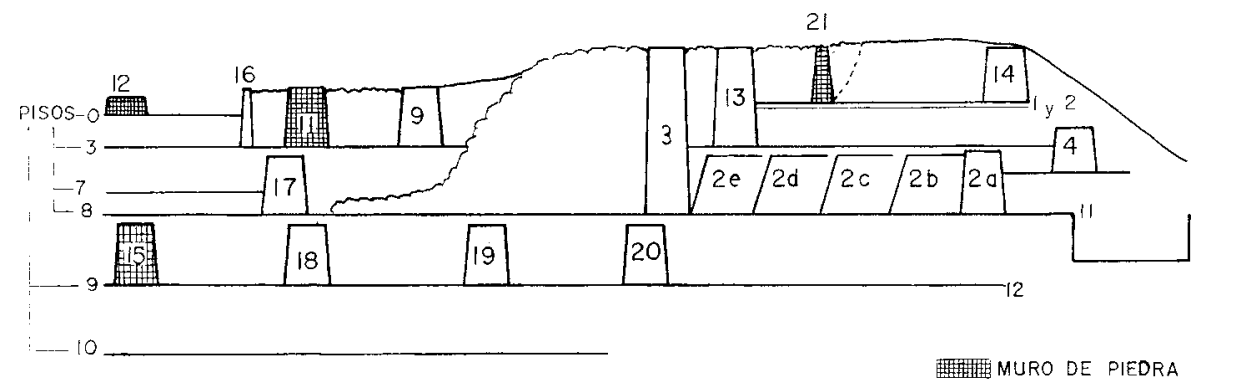

Fig. 4 - Diagrama de la secuencia ocupacional de Baños de Boza. 
Resulta interesante, además, la presencia de una serie de cuatro muros incompletos adosados de Este a Oeste (Fig. 4: 2e-2a), que muestran caras internas finamente enlucidas (incompletos pues se hallan en el perfil oeste) y que muestra una superficie

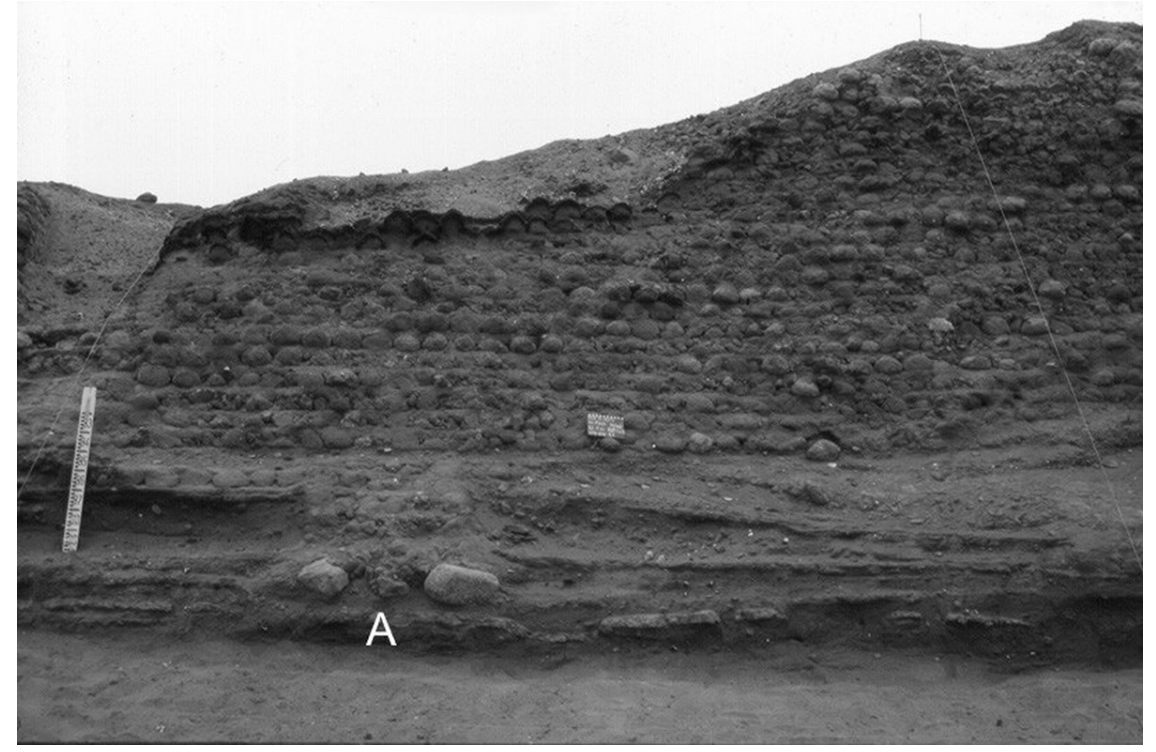

Fig. 5 - Perfil oeste mostrando la plataforma principal. A: muro 19 con cimientos y piedra.

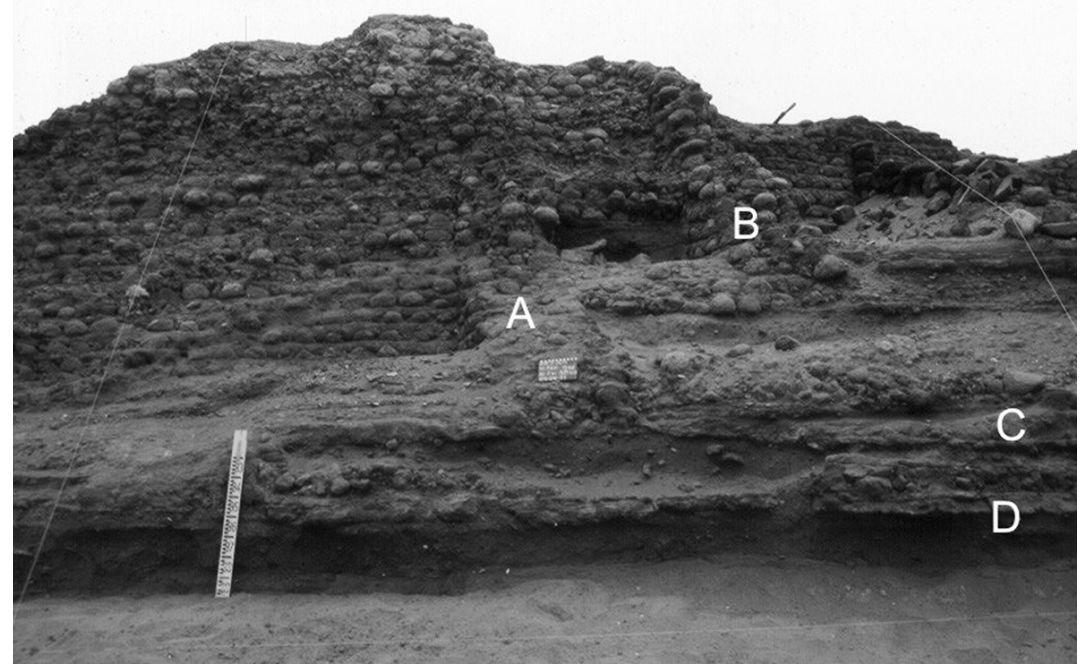

Fig. 6 - Detalle de la arquitectura en el perfil oeste. A: muro 3; B: muro 13; C: piso 11; D: piso 12. 
interna finamente enlucida. Otro componente importante se ubica al sur; es una pequeña habitación de muros enlucidos que correspondía a un depósito, por la presencia de un alto volumen de mazorcas de maíz. Desde esta fase disminuyen los materiales culturales pues los constructores tienden a limpiar los rellenos.

Posteriormente, la fase 5 también se define en el área sur y se inicia con la colocación del piso 4, es entonces cuando se construye el muro 13 y, poco después, los pisos 1 y 2 (Fig. 7, B y C) que sustentan los muros 21 y 14. La última etapa constructiva se parecía mejor en la cima del sitio y consiste en un gran recinto cuadrangular y rodeando un piso pintado de amarillo (Figs. 8, 9). Esto se complementa con una serie de recintos pequeños en el flanco norte, lo cual coincide con las descripciones de Willey.

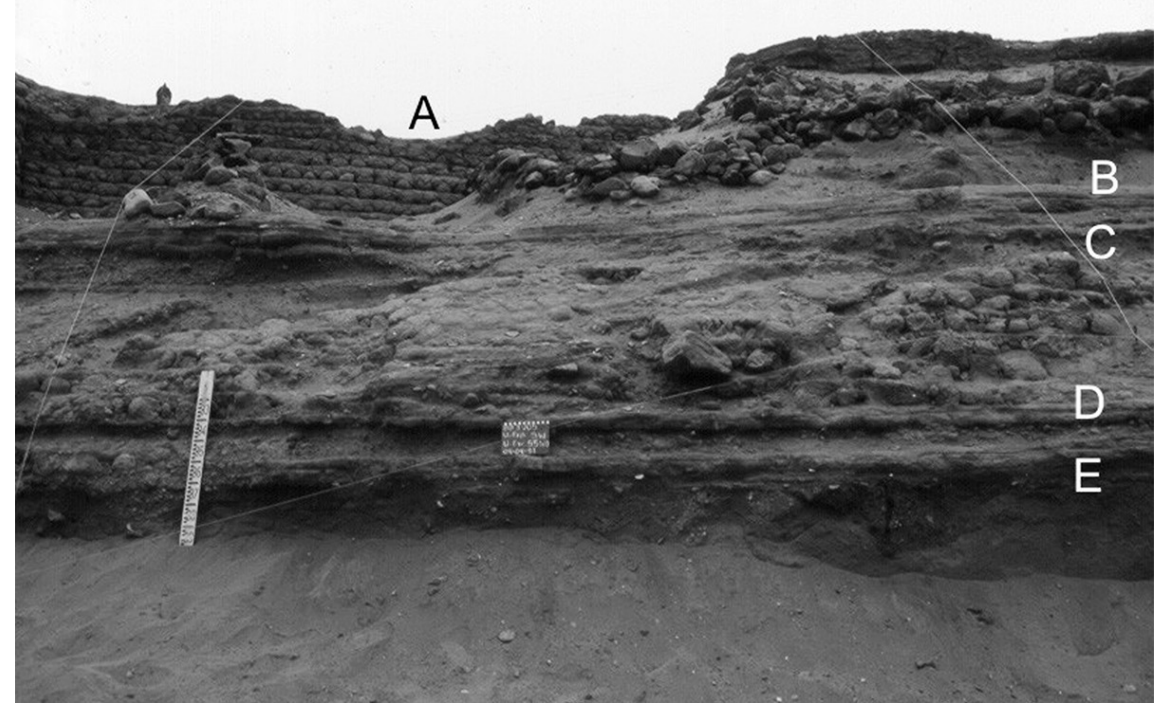

Fig. 7 - Detalle de la arquitectura en el perfil oeste. A: muro 1; B: piso 1; C: piso 2; D: piso 11; E: piso 12.

También podemos encontrar afinidades arquitectónicas entre Baños de Boza y la primera fase de Villa el Salvador. La arquitectura en Villa el Salvador es bastante expresiva pues sus muros están construidos con adobes plano-convexos unidos con argamasa de barro, sobre bases de piedras y con un enlucido fino (Stothert \& Ravines, [1977]: lam 2); un conjunto de rasgos que se repiten en Baños de Boza. Debemos mencionar, además, la presencia de restos de postes próximos a los muros en Villa el Salvador, fenómeno similar a los hoyos de poste asociados a los muros en la cima de Baños de Boza. Lamentablemente el alto grado de destrucción de Villa el Salvador no permitió a los investigadores definir plenamente la función de la arquitectura, lo cual hubiese facilitado las comparaciones con Baños de Boza. No obstante, se postula un uso ceremonial, por la presencia de una plaza hundida, que supuestamente daba a una plataforma hoy destruida, rodeada de pasadizos y cuartos. 


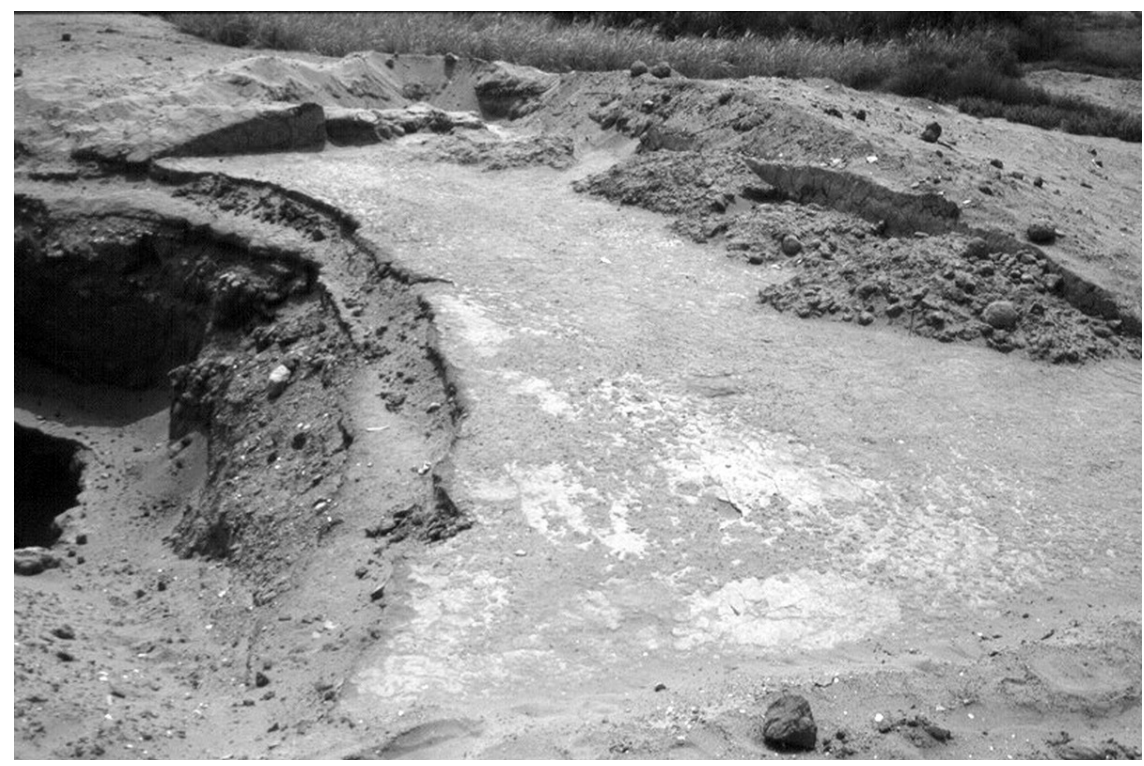

Fig. 8 - Recinto público en la cima del montículo. Nótese el pozo de Willey al oeste reexcavado, con la superposición de pisos.

La limpieza del perfil oeste en Baños de Boza no solamente reveló la secuencia constructiva del sitio, sino que nos mostró aquellas áreas cuyas características permitiesen realizar excavaciones propiamente dichas. De esta manera, se seleccionaron y se excavaron las unidades N11-15 W1-3 y N3-S1 W3 (Fig. 10).

\section{CRONOLOGÍA DE BAÑOS DE BOZA}

La unidad N11-15 W1-3 se ubicó en el extremo norte del sitio. La estratigrafía se caracterizaba por una alta incidencia de capas orgánicas con material cultural que consistía principalmente en cerámica y material malacológico, lo cual evidenciaba una actividad doméstica intensa. También se hallaron hasta ocho pisos de barro, que se correlacionaban bien con las fases constructivas. En total, en el sitio se definieron 28 niveles (Fig. 11).

La unidad N3-S1 W3 se ubicó en la base de la plataforma superior. La estratigrafía constaba de 22 niveles incluyendo cuatro pisos que alternaban con capas de material orgánico y rellenos delgados. En este área tenemos una menor incidencia de material cultural el cual llega hasta la tercera fase de ocupación, como veremos más adelante (Fig. 12).

El análisis de la cerámica reveló detalles importantes respecto a pasta, decoración y forma que se complementan con la información de Willey. El estudio de formas fue útil y necesario dado que Willey no considera este rasgo en su cronología. Dicho autor utilizó una tipología basada en rasgos decorativos y muchos de sus tipos tenían características muy generales como el White Decorated, que incluía varias clases de 

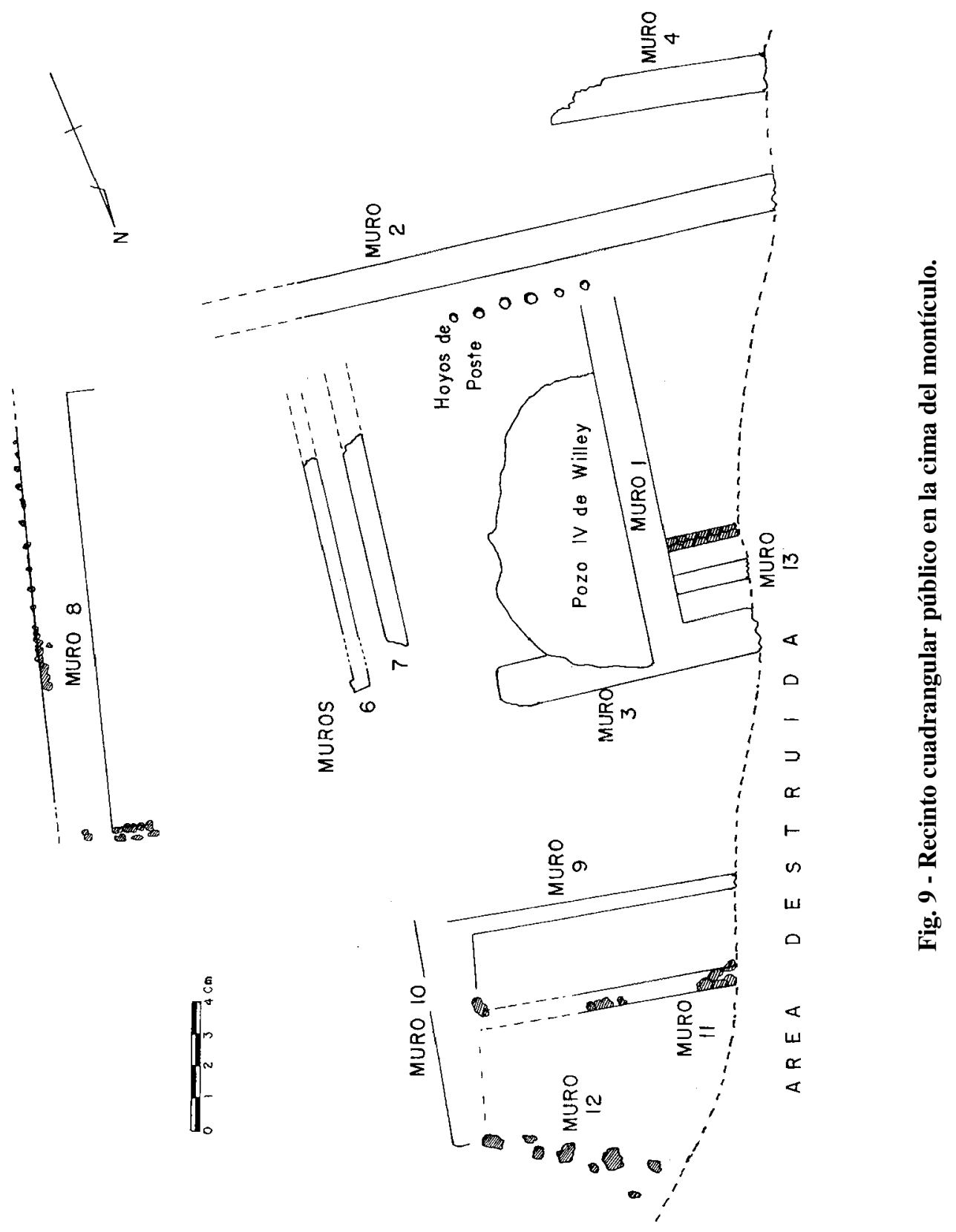


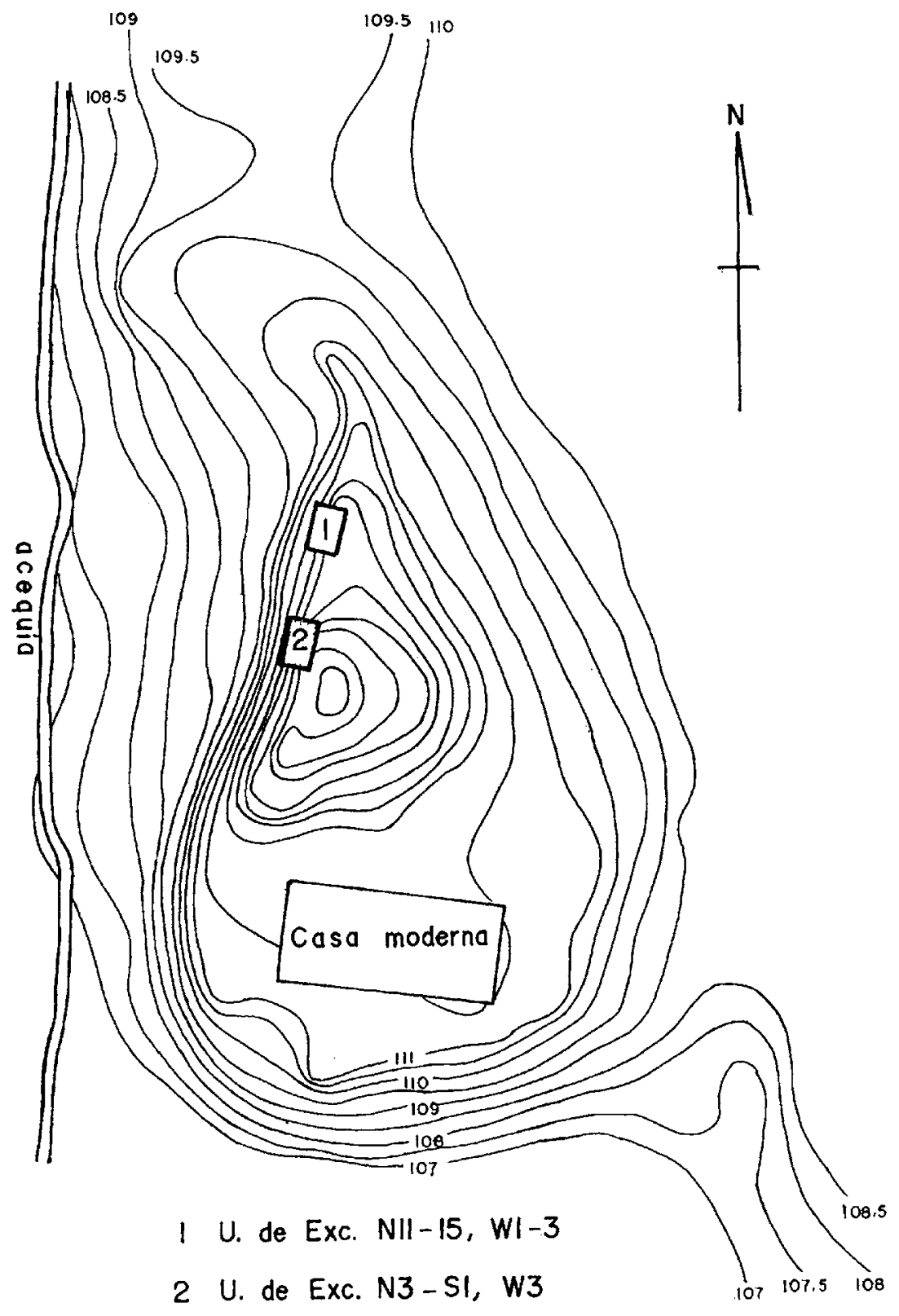

Fig. 10 - El sitio de Baños de Boza con las áreas de investigación. 


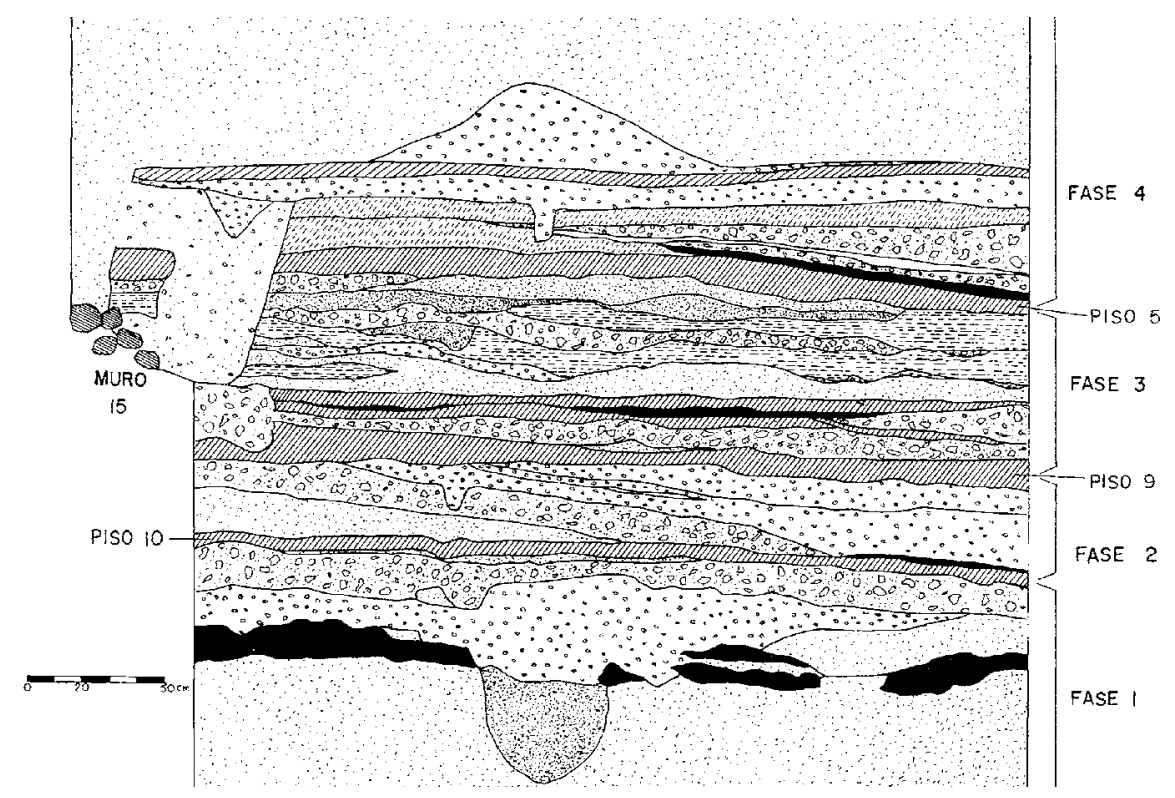

Fig. 11 - Perfil de excavación N11-15 W1-3 con las fases de secuencia cerámica.

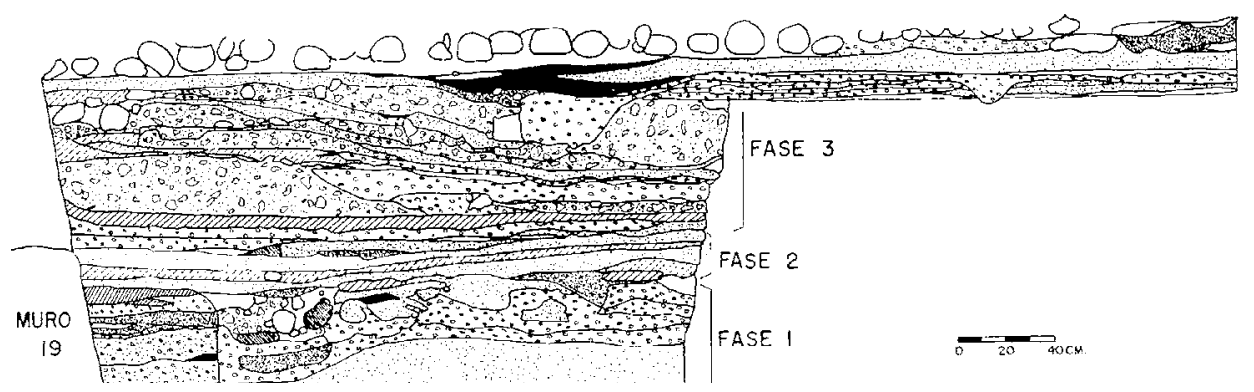

Fig. 12 - Perfil de excavación N3-S1 W3 con las fases de secuencia cerámica.

diseño en ollas y platos. Esta información, cruzada con los datos estratigráficos, nos permitió definir varias fases cerámicas.

La cerámica de Baños de Boza se desarrolla en cuatro fases que guardan relación con las fases constructivas. Esta secuencia cerámica se basa principalmente en los datos de la unidad N11-15 W3 por contener mayor volumen de cerámica y por que abarca toda la secuencia ocupacional del sitio. Estos datos se complementan con los de la unidad N3S1 W3, si bien la estratigrafía de este sector se desarrolla hasta la fase 3 de ocupación. Estas fases se delimitan mejor según los pisos que sellan ocupaciones. A la vez podemos establecer algunas correlaciones entre fases con otras cronologías de la costa central. 


\section{Fase 1.}

Comprende la primera fase constructiva, es decir, desde los niveles más profundos sin arquitectura hasta el piso 10. La cerámica consiste en ollas de paredes gruesas, cuello corto afilado y decoradas con una franja blanca alrededor (Fig. 13, a, b). En segundo lugar aparecen ollas de cuello corto redondeado y hombros bajos (Fig. 13, d, e). Un elemento interesante son las ollas sin cuello, típicas del anterior Horizonte Temprano (Fig. 14, a-d). Finalmente, tenemos un tipo de platos con inflexión interna (Fig. 14, e, f).

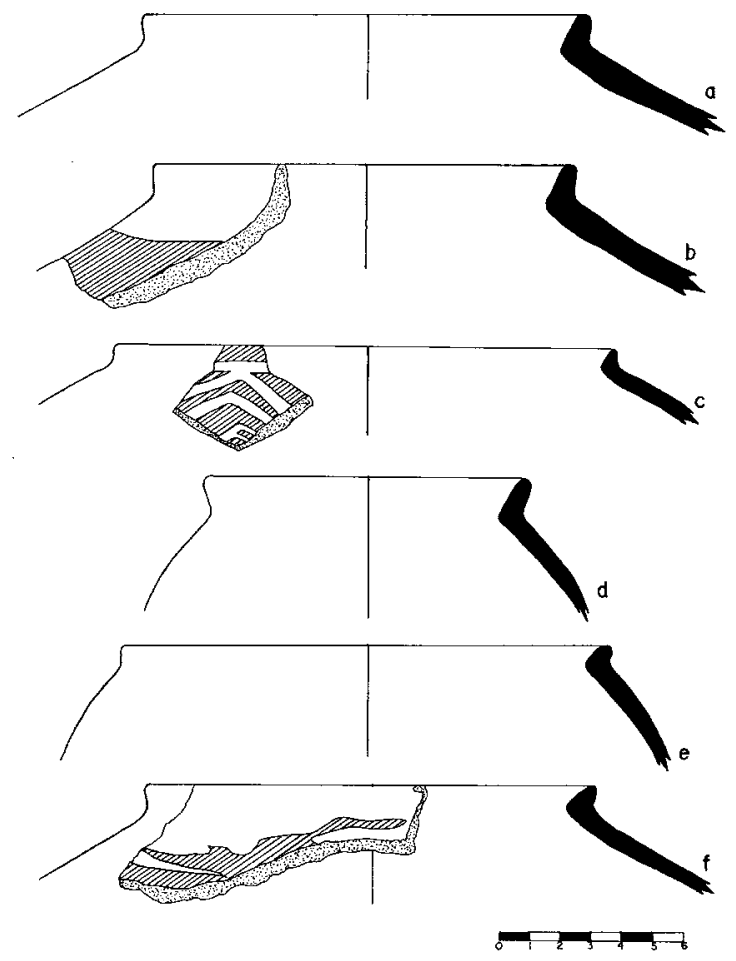

Fig. 13 - Cerámica de la fase 1.

La decoración de franjas blancas en el cuello y las ollas sin cuello son también rasgos comunes de la fase Base Aérea de Miramar (Patterson, 1966: plate 1b y c). A la vez, nuestros platos con inflexión interna son similares a los Unique Bowl de la fase Base Aérea. También, el Bowl 3A de Patterson sería equivalente a los platos de paredes rectas y ambos tienen una prolongada existencia.

Fase 2.

Transcurre en la segunda etapa constructiva del sitio (entre los pisos 9 y 10). Algunos elementos de la fase anterior continúan como la olla sin cuello tipo 1 y ollas con borde redondeado y hombros bajos. Aparecen rasgos nuevos como son cántaros de 


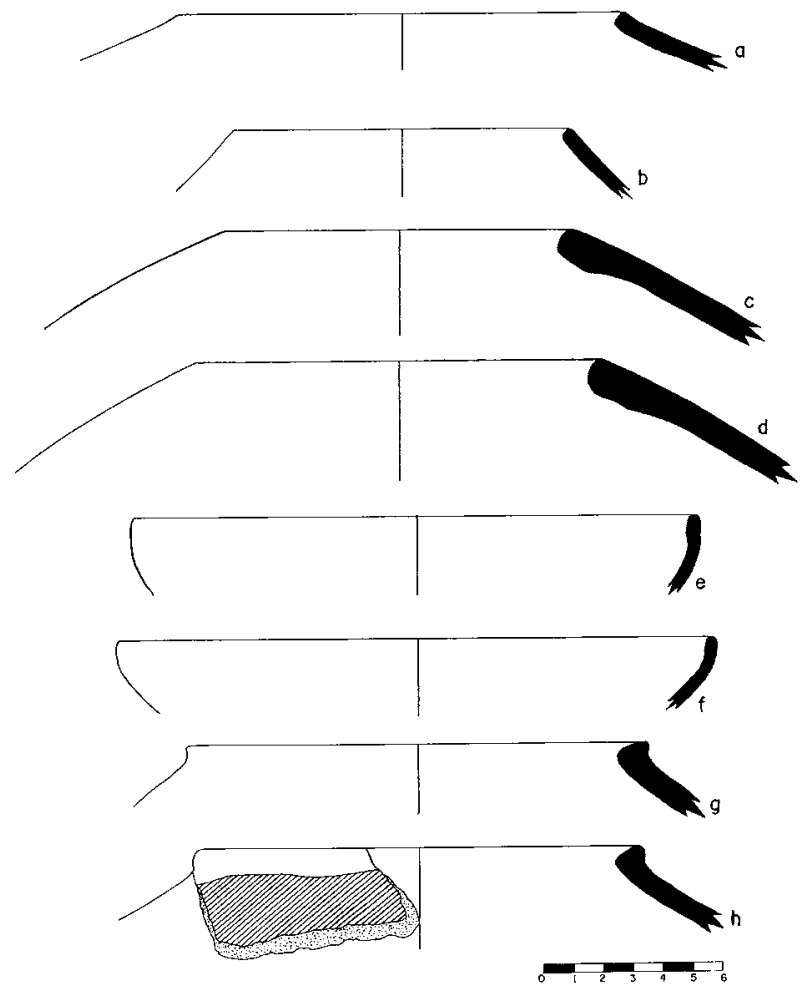

Fig. 14 - Cerámica de la fase 1.

cuello plano convexo (Fig. 15, a, b) y ollas sin cuello con hombros bajos (tipo 2, Fig. 16, a, b). Los platos, a la vez, se diversifican (Fig. 15, e-j), al igual que los cántaros.

Aquí podemos encontrar algunos elementos en común con la segunda y tercera fase de Miramar. El principal es la decoración Rojo sobre Blanco que aplica en los Bowls 4 A (Patterson, 1966: 21), los cuales son similares a las ollas sin cuello tipo 2 halladas en Baños de Boza.

En esta época ciertos platos carenados tienen un acabado bruñido interno en patrón vertical y diseños blancos en la cara externa. Los platos se decoran en la superficie interna con líneas blancas cortas en grupos de 8 ó 9 que penden del labio; mientras que la cara externa suele tener engobe blanco. Otros platos tienden a decorarse con una delgada franja marrón en el labio que es más visible en la superficie externa, alternando con los colores rojo y blanco. Las ollas sin cuello se decoran con pintura roja sobre superficie blanca.

En esta fase aparece también el estilo Lumbra, definido por Patterson (1966: 99), que va a mantener su vigencia durante toda la secuencia. Se caracteriza por el uso de una pintura blanca amarillenta, líneas delgadas y siempre sobre una superficie marrón bruñida. Los diseños consisten principalmente en rombos consecutivos con puntos internos y líneas paralelas (Fig. 17). 


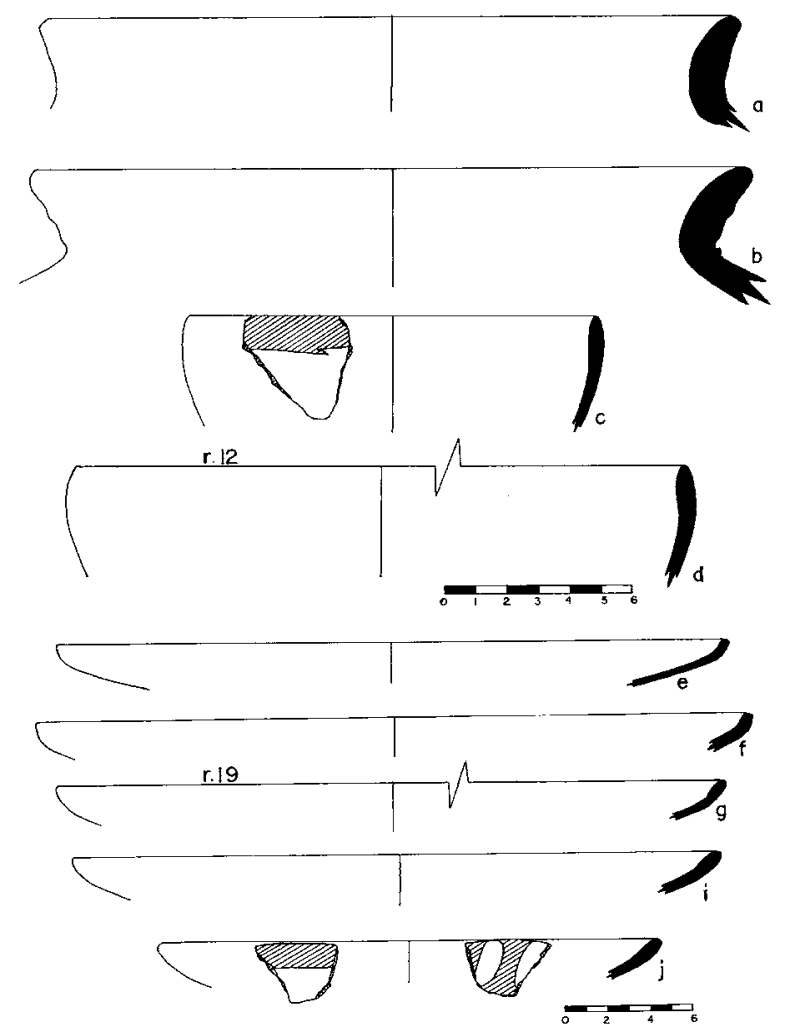

Fig. 15 - Cerámica de la fase 2.

\section{Fase 3.}

Comprende la tercera y parte de la cuarta fase de ocupación de Baños de Boza (hasta el piso 5 de la unidad N11-15 W1-3 y el nivel 10 de la unidad N3-S1 W3). Se caracteriza por la presencia de ollas de cuello alto vertical (Fig. 18, a-c) similares a las ollas 3A de Miramar (fases Polvorín y Urbanización). Aparece, además, un nuevo repertorio de platos que se distingue según el labio (Fig. 19) y de ellos resalta un tipo de base carenada. Por otro lado son más frecuentes los cuencos (Fig. 18, i, k) y los cántaros de cuello cóncavo (Fig. 18, g, h). Respecto a la decoración, continua el diseño de línea marrón sobre el labio de platos y el patrón bruñido vertical.

Fase 4.

Comprende desde la fase 4 hasta los últimos momentos de ocupación del sitio. En esta fase prosiguen las ollas de cuello alto vertical. Otras ollas tienen paredes cóncavas en la mitad superior (Fig. 20, b, e). Los platos son variados y persiste el tipo carenado en la base (Fig. 21, e, f). En esta última fase aparecen las tazas, caracterizadas por sus paredes delgadas verticales (Fig. 21, a, b).

Para esta época, los platos son decorados, también, con una tenue franja roja próxima al borde en la superficie interna de los platos. Por otro lado, las líneas del patrón 


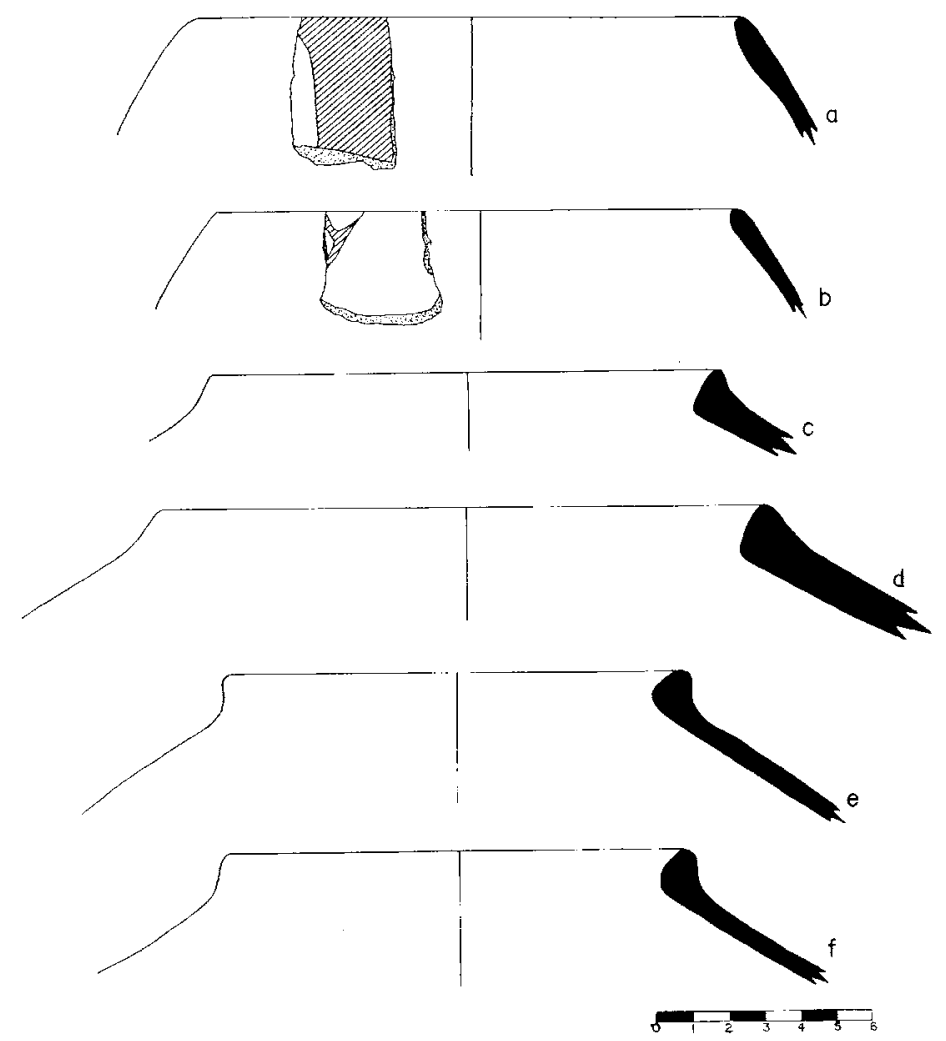

Fig. 16 - Cerámica de la fase 2.

bruñido en platos se orientan de manera diagonal. Ciertos rasgos de esta fase pueden ser comparados con los de la fase Tricolor de Miramar (Lanning, 1963) y Lima 1 como los platos de base carenada y otras piezas decoradas con pintura negra (Fig. 21).

Otros tipos de decoración menos frecuente o que aparecen fuera de contexto son: combinación de líneas y círculos, líneas verticales en ollas, negativo, semicírculos y triángulos en platos y líneas bruñidas en la cara externa de ciertas ollas. De la misma manera, hallamos fragmentos de figurinas, piruros y antaras. Además, un elemento constante en toda la secuencia son las piezas mamiformes, frecuentemente engobadas de blanco y construidas con la técnica del anillado.

No podemos dejar de mencionar la presencia de un estilo que hace su aparición desde la fase 2 conocido como Lumbra (Patterson, 1961-1966: 110). Como puede observarse (Fig. 17), el patrón de diseños es más complejo en relación a los otros especímenes Blanco sobre Rojo y se asocia a piezas de paredes rectas divergentes. Según Patterson (1966), este estilo tiene una filiación norteña, específicamente con el Callejón de Huaylas. Bennett, al respecto, muestra una pieza procedente de Willkawaín con paredes divergentes rectas decorada con líneas en zig zag y puntos, asignada cronologicamente al Blanco sobre Rojo. (Bennett, 1944: 37 y fig. 31 R). De igual manera, Luis G. Lumbreras 


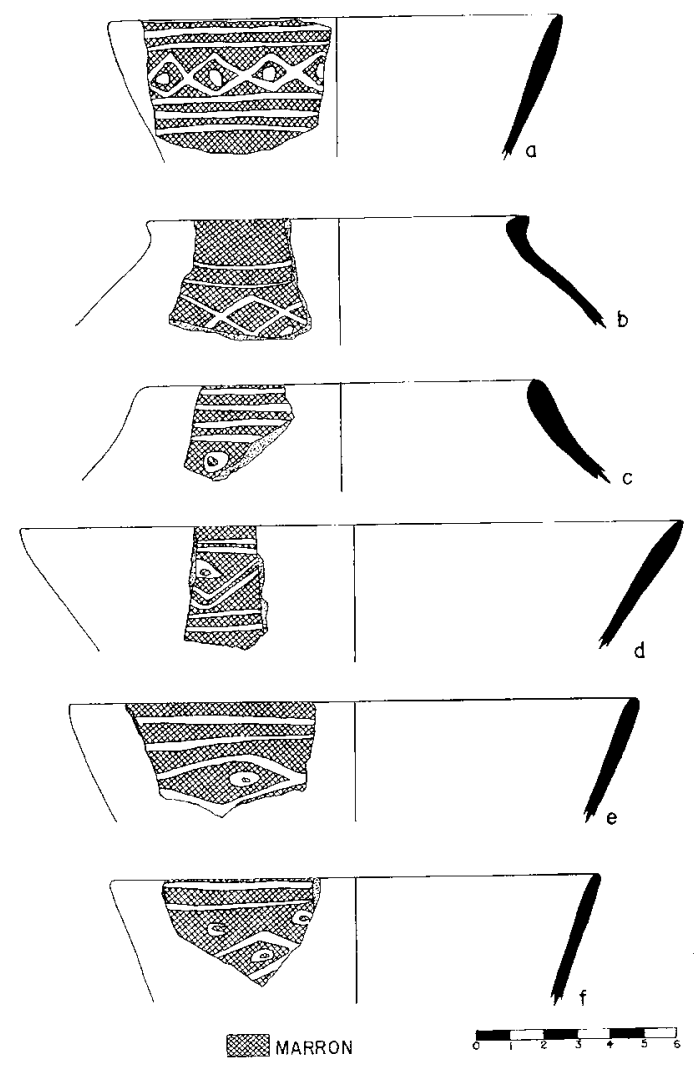

Fig. 17 - Cerámica Lumbra.

(1970), según sus excavaciones en Chavín de Huantar, define una fase estilística Post Chavín denominada Huaraz, con rasgos similares a Lumbra.

Además, Lumbra no sólo se distingue por su forma y decoración sino también por su pasta. Esta es de un color marrón semicompacto con poco temperante pero donde puede distinguirse el feldespato. El análisis de pasta nos permite, también, ampliar el rango morfológico asociado a Lumbra y podemos apreciar un tipo de grandes ollas con paredes gruesas, reborde redondeado grueso y con acabado de líneas bruñidas (Fig. 16, e, f).

La bibliografía arqueológica nos muestra claramente las vinculaciones alfareras entre Baños de Boza y Cerro Trinidad, y nuestra investigación esclarece aún más este panorama. Ambos sitios comparten ollas ovaladas con cuello corto, con o sin asas cintadas horizontales, cántaros mamiformes, platos hondos y cuencos. Otros especímenes son cántaros globulares con carena y cuello alto. Algunos elementos muy típicos del Blanco sobre Rojo aparecen en Cerro Trinidad y escasamente en Baños de Boza como es la compleja decoración pintada en la mitad superior de las ollas cuyos diseños varían en el tiempo según la secuencia de Patterson. Dicha decoración consiste en líneas en zig zag que forman triángulos o rombos con puntos o anillos internos. 

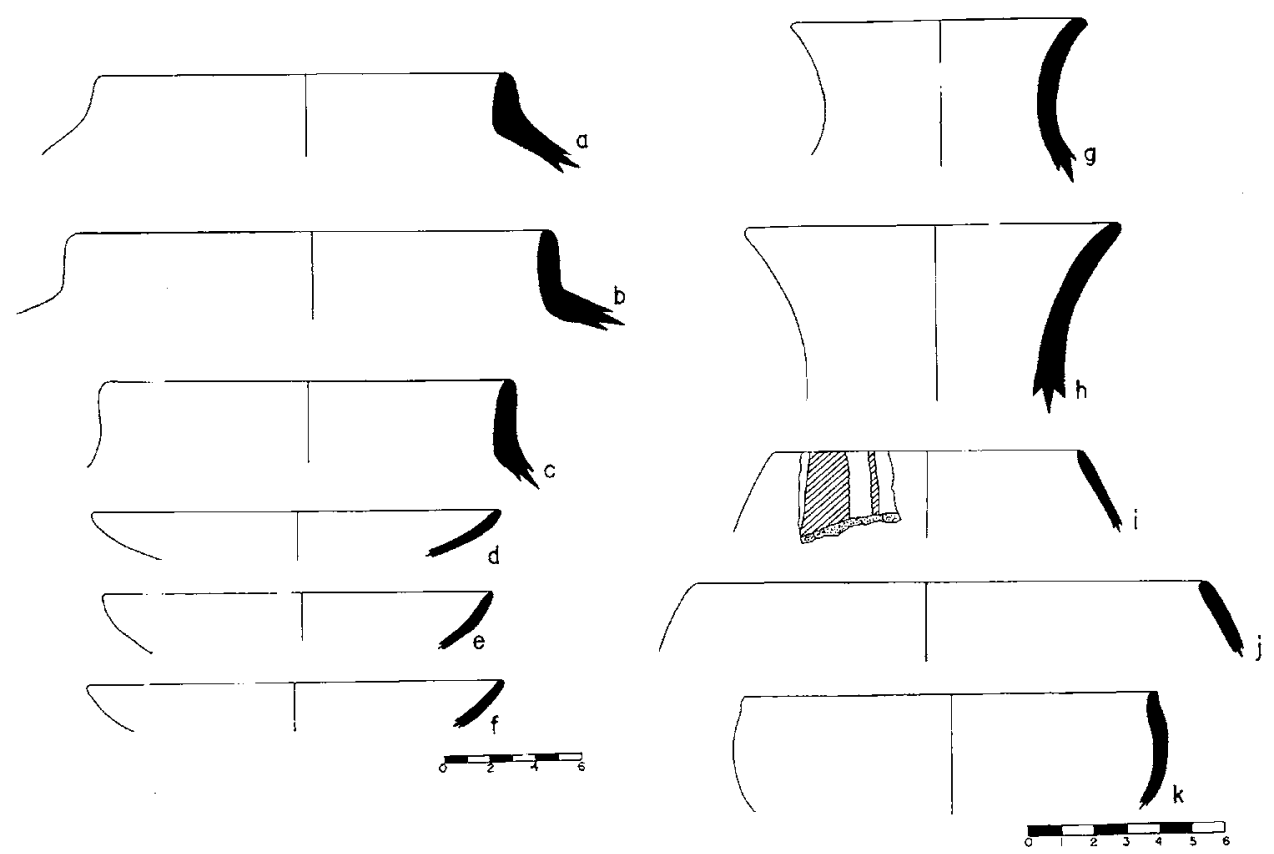

Fig. 18 - Cerámica de la fase 3.

No menos importantes son las semejanzas estilísticas con el valle del Rímac, específicamente en el área de Huachipa Jicamarca. Al respecto, las excavaciones de Silva \& García (1997) establecen una buena cronología. En sus materiales encontramos cuellos de cántaro (que Silva denomina jarra), ollas, cuencos y platos hondos, algunos con decoración en pintura blanca. En la fase Huachipa-Jicamarca D1 encontramos platos hondos similares a los de Baños de Boza (García \& Silva, 1997: Fig. 22 1-r). Al mismo tiempo se observa ollas sin cuello (Op. Cit. fig. 24) de labios biselados y dos jarras de cuello alto similar a nuestras ollas con cuello (Op.Cit. fig. 25 i-j). De igual manera, encontramos diseños en Rojo sobre Blanco (Op. Cit. fig. 28 j-k). En la fase Huachipa-Jicamarca D2 hay un incremento de cuencos mientras continúan los cántaros, botellas de doble pico y gollete, y la decoración Blanco sobre Rojo.

Las investigaciones de Silva y García se complementan con las que realizara Jonathan Palacios (1987-1988), en la misma zona pero mediante metodología distinta. Las fases de Palacios, Huayco Temprano y Huayco Medio muestran similitud de rasgos con Baños de Boza por la presencia de ollas de cuello alto, de hombros bajos, platos hondos así como botellas de doble pico similares a los que encuentra Uhle en Cerro Trinidad (Kroeber, 1926: plate 90 A y C).

Hacia el norte, en la actual ciudad de Végueta, valle de Huaura, se halló cerámica Blanco sobre Rojo y Lima pero con rasgos muy peculiares (Shady \& Ruíz, 1979). Algunos elementos en común con Baños de Boza consisten en ollas con cuello alto divergente y platos hondos. La decoración pictórica en Végueta es muy variada 

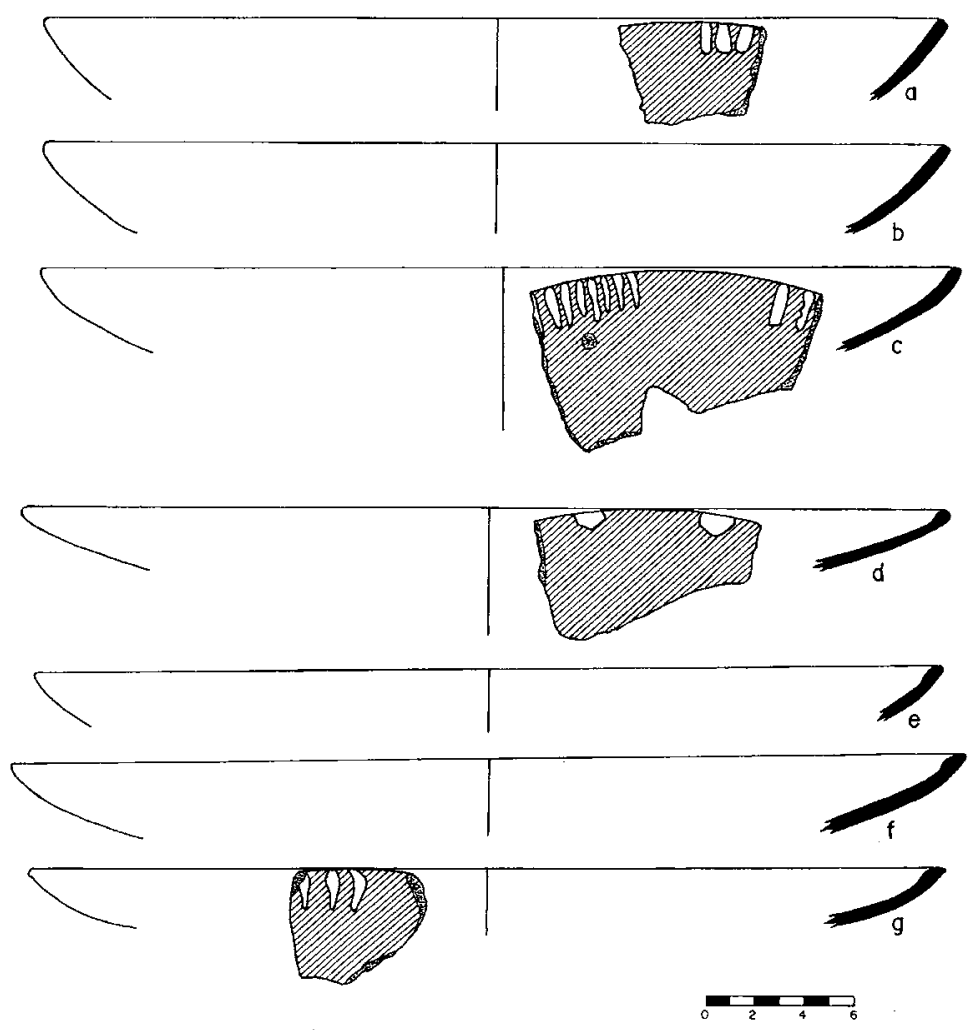

Fig. 19 - Cerámica de la fase 3.

predominando la técnica del Rojo sobre Blanco pero con diseños que en el valle de Chancay se ejecutan en Blanco sobre Rojo. Sin embargo, el uso de la pintura Blanca claramente muestra una filiación Lumbra y similar a nuestros especímenes (Shady \& Ruíz, 1979: Fig. 6 d, e y g). Otros tipos de diseño son las líneas incisas, que encontramos en los niveles más profundos de Baños de Boza (Fig. 22, c, capa 19, Fase 2)

Hacia el sur, en el valle de Lurín, Villa el Salvador (Stothert \& Ravines, 1977) no sólo es importante por su arquitectura sino por su variada alfarería (Delgado, 1992), la cual es muy similar a los especímenes recuperados de Tablada de Lurín (Cárdenas, 1980; 1999). Al hacer las comparaciones con Baños de Boza, descubrimos que las diferencias son mayores, especialmente con Tablada de Lurín, lo cual sugiere un desarrollo estilístico independiente en este valle. Respecto a Villa el Salvador, las semejanzas estilísticas que mantiene con Baños de Boza se refiere en general a ollas ovaladas con cuello o reborde, cántaros, platos hondos y diseños en Blanco sobre Rojo y Rojo sobre Blanco. La forma de los cuellos suele ser variable aunque tienden a ser rectos lo mismo que el labio (Stothert \& Ravines, 1977: Figs. 5 d-j y 6 c-e). También encontramos platos hondos (Op. Cit.: Fig. a-h) y ollas sin cuello (Stothert \& Ravines, 1977: Figs. 9 j-1 y 15 e-f), estas últimas tiene formas de los labios muy variables. Las 


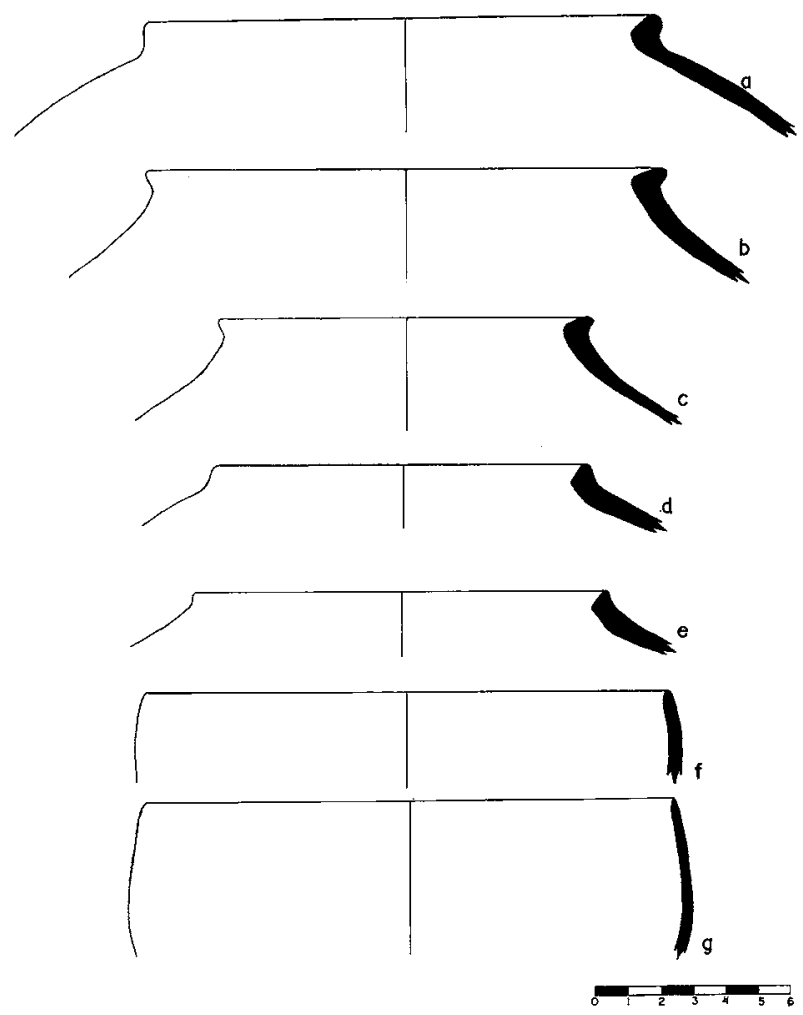

Fig. 20 - Cerámica de la fase 4.

piezas zoomorfas y las botellas de doble pico también son frecuentes en Villa el Salvador y pueden ser comparables con los especímenes de Uhle (Kroeber, 1926: plate 86 f-g; 89 f y 90 a, b y c). En cuanto a la decoración, se utiliza la pintura blanca para producir puntos, franjas en los cuellos y líneas verticales; a la vez que encontramos una alta incidencia de diseños Rojo sobre Blanco que representan motivos Interlocking.

\section{EL BLANCO SOBRE ROJO Y LIMA}

En esta investigación teníamos particular interés en esclarecer las relaciones cronológicas entre el Blanco sobre Rojo y Lima. Muchos investigadores afirmaban en base a argumentos estratigráficos que el Blanco sobre Rojo y Lima constituían dos tradiciones con características distintas, coexistentes durante cierto lapso de tiempo vg. las investigaciones de Playa Grande y Cerro Trinidad. Solamente en el área de AncónChillón la secuencia de Patterson hace ver una relación evolutiva unilineal del Blanco sobre Rojo a Lima mediante una fase transicional denominada Tricolor. Sin embargo, como vimos antes (página 4), debemos considerar que no hay un sustento estratigráfico para todas las fases Miramar. La ubicación de la fase transicional conocida como Tricolor, así como sus relaciones con las fases Urbanización y Lima 1, se hizo en base a seriación. 


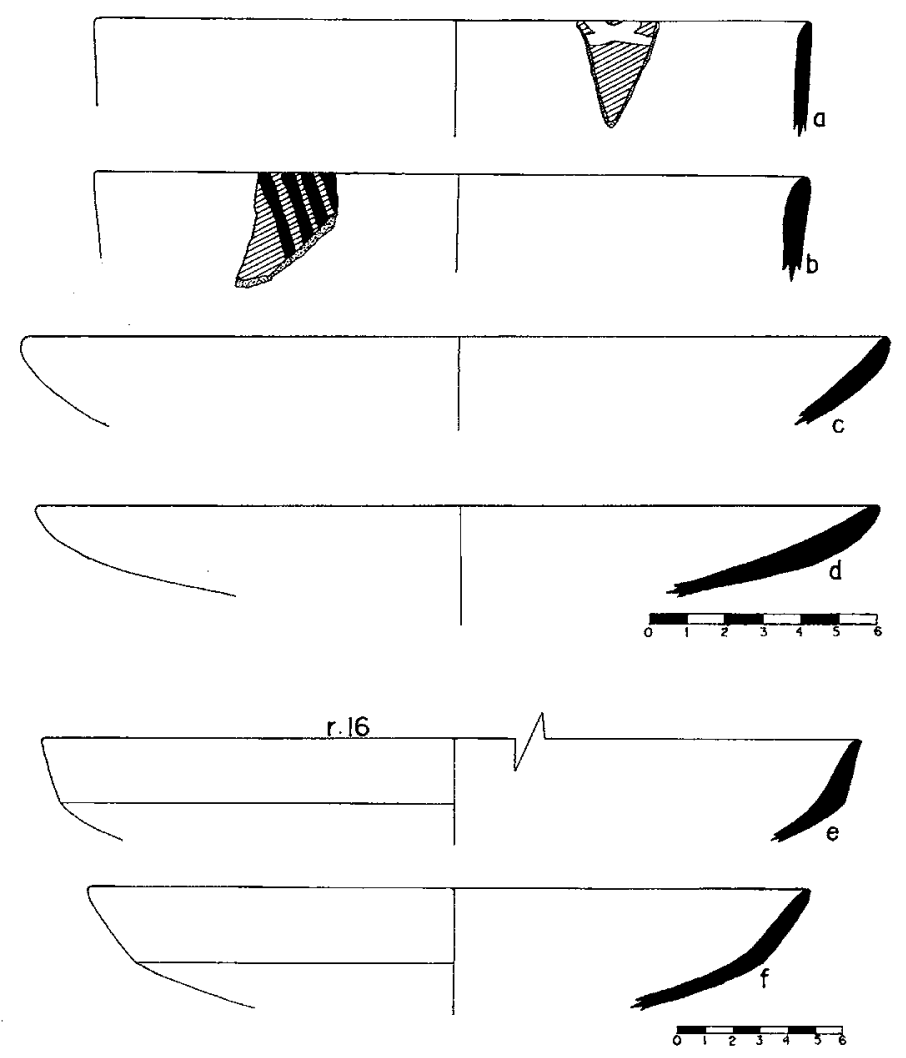

Fig. 21 - Cerámica de la fase 4.

Las relaciones Blanco sobre Rojo-Lima pueden entenderse mejor evaluando la información estratigráfica de excavaciones anteriores, como podemos hacerlo en Cerro Trinidad y Playa Grande. De esta manera podemos hallar cierto lapso de contemporaneidad entre el Blanco sobre Rojo y Lima, y definir que rasgos de ambos estilos coexisten.

\section{1. Investigaciones en Cerro Trinidad}

En este lugar Willey excavó siete pozos de los cuales muestra las tablas porcentuales de los pozos IV, V, VI y VII. Un rasgo notable en estas tablas es la ausencia de tipología formal, aunque se mencionan brevemente algunos rasgos morfológicos relacionados a los decorativos. Además, la tipología Blanco sobre Rojo es menos refinada en relación al Interlocking pues los diseños Blanco sobre Rojo se agrupan en un solo tipo: White decorated. Los tipos Engobe Blanco y Zonas Blancas tienen una distribución continua y se asocian a ollas ovaladas y cántaros mamiformes, ambos contemporáneos con Lima.

En Cerro Trinidad se puede fechar elementos del estilo Lima mediante el esquema de Patterson, en cierta medida. Patterson había revisado los datos de Willey 
especialmente de los pozos IV y VII, descubriendo que la cerámica Interlocking sobre el piso E correspondía a Lima 4. La cerámica Lima entre los pisos E y G corresponde a las fases 2 a 4 y consiste en grecas con cabezas triangulares entrelazadas, puntos y círculos (estos últimos se ubicarían mejor en la fase 5). Estos rasgos Lima aparecen contemporáneos, según las tablas estratigráficas de Willey, a Rojo sobre Blanco, Engobe Blanco, Zonas Blancas y White decorated, correspondientes todos estos a la tradición Blanco sobre Rojo.

\section{2. Investigaciones en Playa Grande}

En este área (Tabío, 1957; 1965), la estratigrafía nos muestra un período de transición entre Playa Grande y Baños de Boza, tal como se observa en el pozo B. Según las descripciones y fotos de Tabío, los elementos más representativos de Playa Grande son los peces entrelazados, presentes en todos los niveles y corresponden a las fases Lima 2-4. En los mismos niveles estratigráficos aparecen fragmentos Blanco sobre Rojo cuya decoración consiste en reticulado en color blanco sobre fondo rojo o marrón, que también son típicos del Tricolor. Resulta interesante descubrir aquí, al igual que en Cerro Trinidad, que las bandas horizontales decoradas en el borde constituyen un rasgo que aparece muy temprano, contemporáneo a Base Aérea. Además, la tipología que maneja Tabío es muy similar a la de Willey pues prescinde de variables de forma.

Finalmente, en Baños de Boza, en los niveles superiores, se recuperó algunos fragmentos con decoración en pintura negra que indicaría una clara afinidad con el Tricolor (Fig. 22, a, b). La presencia de platos de base carenada y tazas señala también una relación cercana a las fases Lima 1-3. Incluso tenemos un tiesto con decoración de tres colores que es similar a otro fechado por Patterson como Lima 3 (Patterson, 1966: Fig. 11h). Pese a ello, no se halló fragmentería con decoración típica Lima, es decir, serpientes biséfalas entrecruzadas.

En resumen, las evidencias en Cerro Trinidad y Playa Grande presentan al Blanco sobre Rojo y Lima como dos estilos plenamente diferenciados en contextos donde coexisten. Estas diferencias no se limitan a la decoración pues los rasgos morfológicos son muy indicativos. Si hacemos una comparación entre nuestra última fase de Baños de Boza y la primera fase Lima descubrimos que en Baños de Boza predominan ollas de cuello corto (Fig. 20, a-e) frente a las ollas Lima de cuello alto (Patterson, 1966: fig. 8 e-f). Además, también se observan diferencias en los platos en cuanto a la profundidad y el grosor de las paredes. Existen, como mencionamos, algunas similitudes como los platos carenados y los cuencos; si bien estas últimas tienen una presencia continua en toda la secuencia de Baños de Boza.

Así entonces, no se observa una evolución o cambio estilístico del Blanco sobre Rojo hacia Lima tal como lo hace ver la seriación de Patterson. Esto puede explicarse por razones metodológicas puesto que una seriación tiende a ser unilineal pues se utilizan sólo aquellos rasgos que encajan en la secuencia seriada. La información estratigráfica, por el contrario, permite ver la variabilidad tipológica por fases, influencias externas y correlaciones con otros eventos culturales en el sitio. 

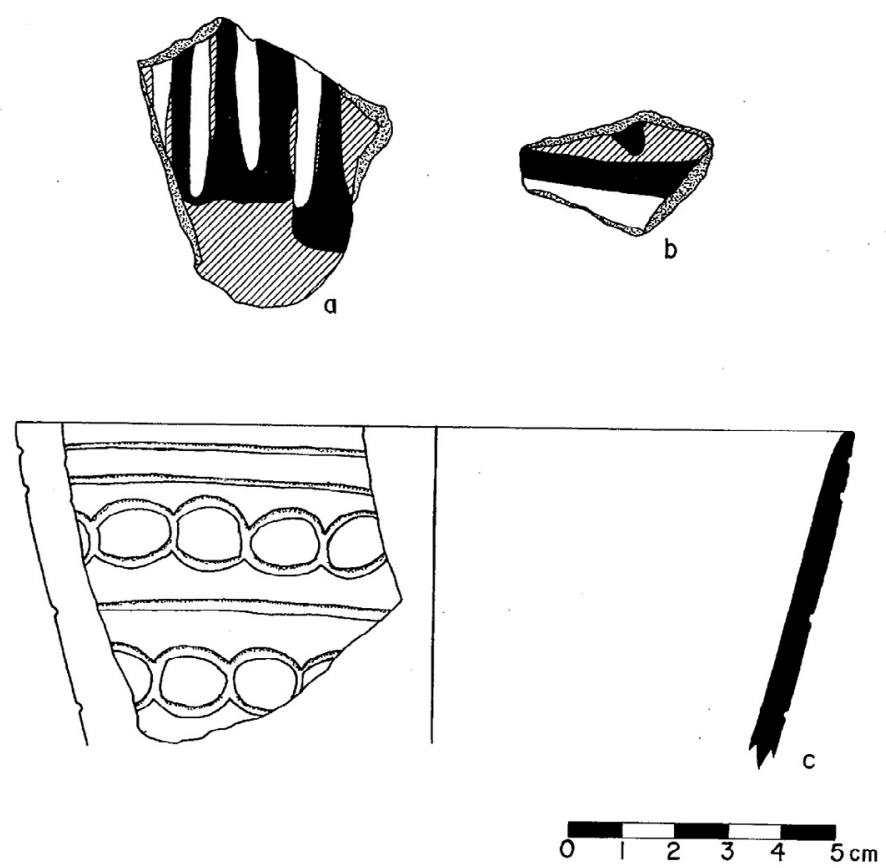

Fig. 22 - a y b: cerámica Lima; c: fragmento. Condecoración incisa procedente de la segunda fase.

Las excavaciones en Cerro Trinidad revelan otro aspecto importante. El estilo Lima irrumpe bruscamente después de la colocación del piso G, como se observa en los pozos IV y VII. A partir de este momento cesa la independencia del Blanco sobre Rojo y este se desarrolla, por un tiempo, paralelamente al estilo Lima. En las investigaciones de Willey hubiese sido interesante descubrir el significado de la colocación de este piso y su asociación con otros eventos constructivos, posiblemente un cambio de función. Lamentablemente, el reducido tamaño de los cateos impide llegar a mayores conclusiones respecto a la arquitectura.

Con estas afirmaciones queremos reforzar la teoría de un orígen foráneo del estilo Lima en Chancay. No tenemos suficientes evidencias para señalar un lugar de orígen del estilo Lima aunque Earle (1972), quien define a Lima como Estado, plantea que pudo ser el valle del Rímac, en el área de Maranga. Sin embargo, la información de Patterson nos permite plantear los orígenes de Lima en Ancón y la parte baja del valle de Chillón, área con una presencia significativa de fragmentos Tricolor o Lima 1.

Poco podemos decir respecto a las características de la ocupación Lima en el valle de Chancay, principalmente por la falta de un estudio de patrón de asentamiento. En nuestros recorridos por la zona de Baños de Boza observamos que la presencia Lima, manifestada en cerámica superficial, era poco significativa. Sin embargo, podemos recurrir a estudios en otras áreas de la costa y elaborar una hipótesis para Chancay. De esta manera, en el valle de Lurín, Earle (1972) propuso una secuencia de seis fases 
señalando los cambios en el patrón ocupacional con la llegada del estilo Lima. Las fases 1 y 2 corresponden al Blanco sobre Rojo y se caracterizan por tener un índice poblacional estable, con asentamientos aislados distribuidos irregularmente en las partes bajas del valle y quebradas, asociados estos a estructuras públicas pequeñas y aisladas. La expansión Lima, vendrá a cambiar todo este panorama, generándose una serie de eventos como la construcción y control de canales de irrigación más grandes, asentamientos aglutinados, una diferenciación jerárquica marcada y el surgimiento de unidades políticas autónomas. La expansión Lima comenzó en la fase tres, desde la parte baja del valle hacia arriba.

Es posible que una situación similar a la de Lurín se viviera en el valle de Chancay, si asumimos que la expansión Lima se dio bajo un sistema homogéneo en todo su territorio. Nosotros podemos agregar, a partir de nuestras evidencias, que las poblaciones Blanco sobre Rojo de Chancay habían alcanzado ya un nivel de desarrollo alto, con presencia de elites político religiosas, como lo evidencian las estructuras públicas en Baños de Boza y el patrón funerario en Cerro Trinidad.

\section{DISCUSIÓN Y CONCLUSIONES PRELIMINARES}

La cronología que hemos definido en Baños de Boza, que incluye algunos elementos foráneos como el estilo Lumbra, no es una secuencia maestra para la costa central ni pretende sustituir el esquema de Patterson. Es una secuencia que se ajusta a los rasgos estilísticos del valle de Chancay que puede ser contrastada con otras cronologías como Miramar y Huachipa-Jicamarca. Debemos considerar que Baños de Boza es un sitio arquitectónico con características funcionales (se trata de una estructura pública) muy distintas a Miramar y Huachipa-Jicamarca y en la cual se ha empleado una metodología de estudio diferente (Tabla 1).

\begin{tabular}{|c|c|c|c|c|c|c|c|}
\hline & $\begin{array}{c}\text { Villa El } \\
\text { Salvador } \\
\text { Stothert, } \\
1977\end{array}$ & $\begin{array}{c}\text { Cerro } \\
\text { Trinidad } \\
\text { Patterson, } \\
1961\end{array}$ & $\begin{array}{c}\text { Baños de } \\
\text { Boza } \\
\text { Córdova, } \\
1999\end{array}$ & $\begin{array}{c}\text { Miramar } \\
\text { Patterson, } \\
1966\end{array}$ & $\begin{array}{c}\text { Huachipa } \\
\text { Silva y } \\
\text { García, } \\
1997\end{array}$ & $\begin{array}{c}\text { Huachipa } \\
\text { Palacios, } \\
1987-88\end{array}$ & $\begin{array}{c}\text { Ica } \\
\text { Menzel, } \\
1971\end{array}$ \\
\hline \multirow[t]{5}{*}{$\begin{array}{l}200 \\
\mathrm{aC} .\end{array}$} & & & & & C & Cerro & Jahuay 1 \\
\hline & $\begin{array}{c}\text { Villa El } \\
\text { Salvador } 1\end{array}$ & $\mathrm{~T} 1$ & Fase 1 & Base Aérea & D1 & Pinazo & Jahuay 2 \\
\hline & $\begin{array}{c}\text { Villa El } \\
\text { Salvador } 2\end{array}$ & $\mathrm{~T} 2$ & Fase 2 & Polvorín & D2 & Huayco & Jahuay 3 \\
\hline & & & Fase 3 & Urbanización & & & Chongos \\
\hline & & $\mathrm{T} 3$ & Fase 4 & Tricolor & & Lima & Campana \\
\hline $\begin{array}{l}400 \\
\mathrm{dC}\end{array}$ & & Lima 3 & Fase 5 & Lima & & & Carmen \\
\hline
\end{tabular}

Tabla 1 - Relaciones Cronológicas entre Baños de Boza, Cerro Trinidad, Miramar, Villa el Salvador, Huachipa e Ica. 


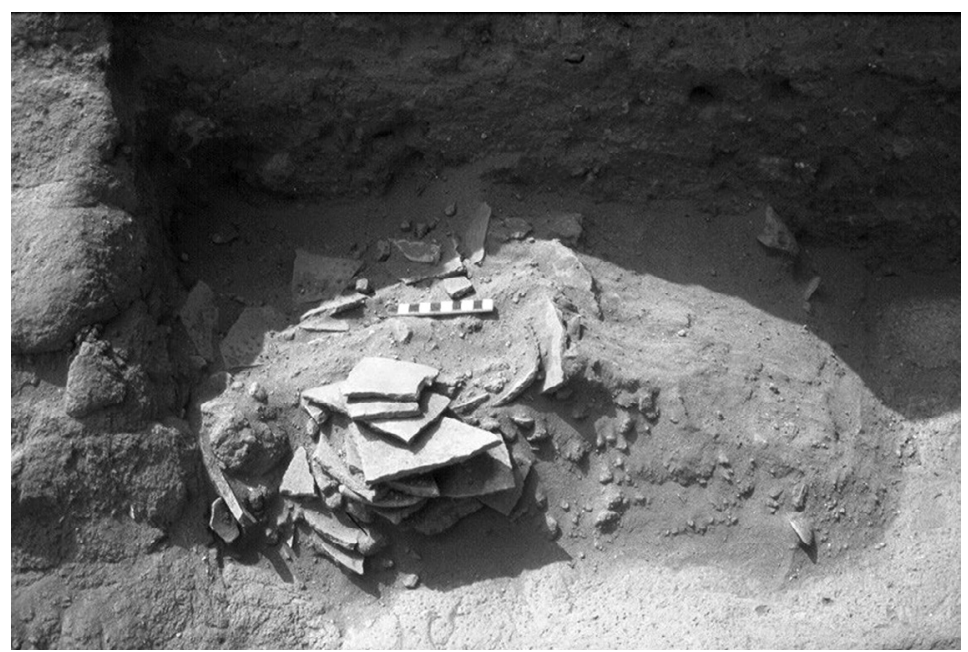

Fig. 23 - Ofrenda fragmentada próxima al muro 19.

En Baños de Boza tenemos nuevas evidencias sobre el nivel de desarrollo alcanzado por las poblaciones del Blanco sobre Rojo. Las primeras ocupaciones (fases 1 al 3) son netamente domésticas, incluso podría tratarse de una pequeña aldea. Luego, desde su fase constructiva cuatro ostenta toda las características de un sitio público dado que su estructura básica esta constituida por cuartos de relleno para la conformación de plataformas. Los hallazgos en la cima del sitio avalan esta idea pues se observa un recinto cuadrangular de paredes enlucidas, un acceso restringido y sellado con cantos rodados por el norte, y un piso finamente pintado de amarillo, sin desgaste (Fig. 5). Este recinto habría estado techado según las hoyos de poste en los lados sur y este, así como los restos de fibras vegetales en los alrededores.

La utilización de una duna natural para edificar una plataforma puede explicarse no solamente por su efecto visual frente a los espectadores que acudían al templo en aquellas épocas. Baños de Boza, hasta hace unas décadas atrás, era un terreno casi pantanoso, donde proliferaban lagunas $\mathrm{y}$, actualmente, tiene un alto contenido de humedad y salinidad que puede afectar las bases de cualquier construcción. Por tanto, resulta muy ventajoso construir sobre montículos.

Además de la arquitectura, existen otros indicadores de actividad ritual en Baños de Boza. En la unidad de excavación N3-S1 W3 nivel 11 se halló una ofrenda de cerámica cuyos fragmentos estaban cuidadosamente colocados en un foso junto al muro 19 (Fig. 23). Dicha pieza, al ser reconstruida, resultó ser un cántaro globular (Fig. 24). Este hallazgo es comparable con otro similar en Playa Grande, donde E. Tabío recuperó dos piezas enteras Blanco sobre Rojo, una de ellas parcialmente rota y colocadas verticalmente. En Végueta, en tanto, Shady y Ruíz encontraron dos tinajas a modo de ofrenda.

Otra vía para interpretar estas ofrendas de cerámica nos la dan los hallazgos en la Huaca Pucllana, estudiados por Huayta Montoya (1995), si bien, correpondientes plenamente a épocas Lima. Dichos eventos se interpretan como un acto ritual de 


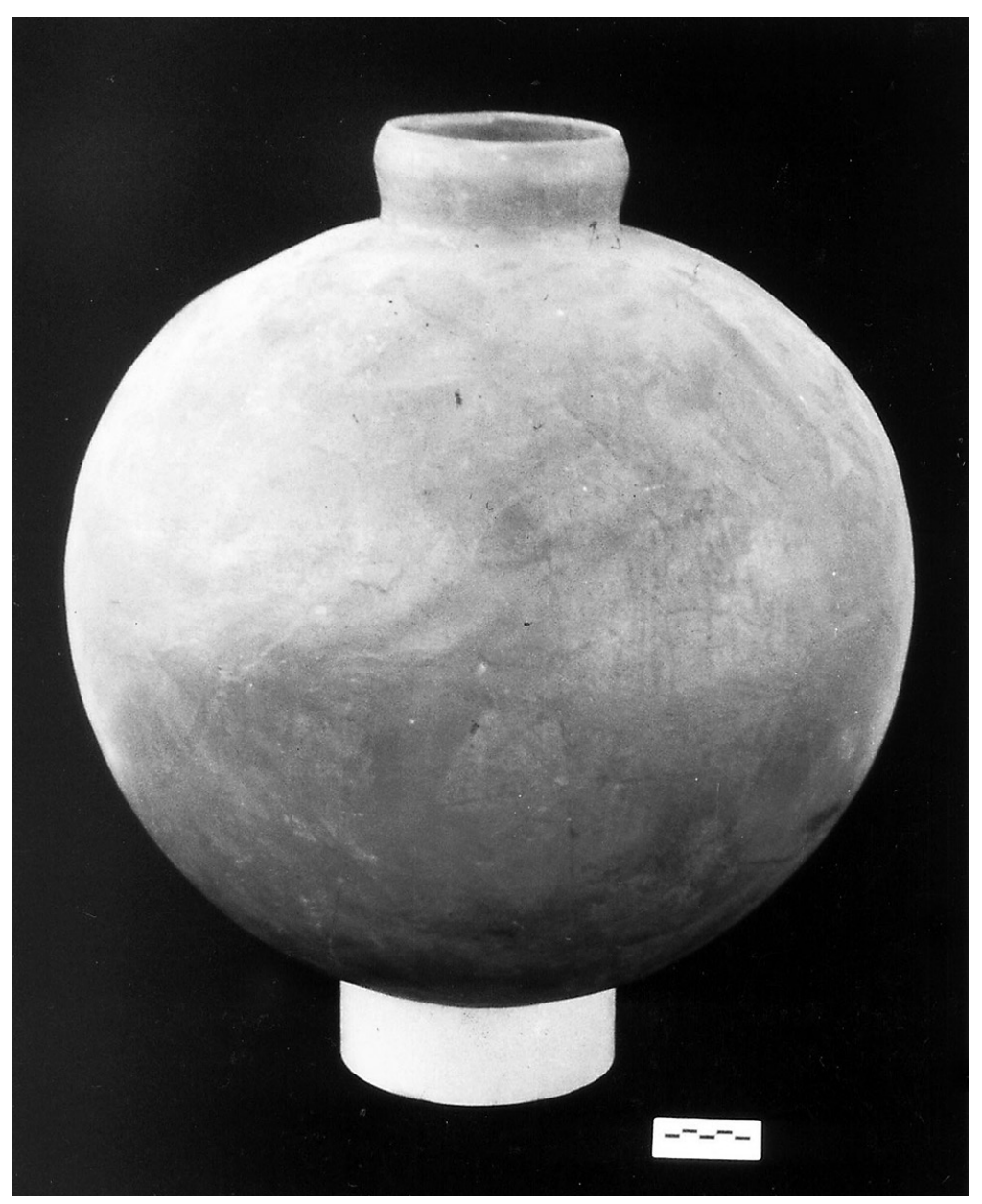

Fig. 24 - Reconstrucción de la ofrenda fragmentada.

clausura y construcción de una nueva plataforma; aún la deposición de rellenos en los que yace la ofrenda corresponde a un acto ritual.

El carácter público de Baños de Boza nos conduce al tema de las relaciones sociales durante el período Blanco sobre Rojo. En esta investigación, podemos plantear algunas hipótesis a partir de los estudios de Patterson y Lanning (1964) en Ancón y el valle bajo del Chillón. Para inicios del Período Intermedio Temprano, las aldeas se asociaban a estructuras ceremoniales y cambian su ubicación desde los cerros hacia los valles o áreas planas cerca al litoral. Otro grupo de aldeas más pequeñas se ubicaban en los límites de los valles. Muchos de estos asentamientos, señalan los autores, habrían desaparecido a causa de la expansión agrícola. Es posible que en el valle de Chancay se diese este mismo patrón y que Baños de Boza, situado en un terreno plano del valle, estuviese relacionado a estructuras domésticas hoy destruidas. 


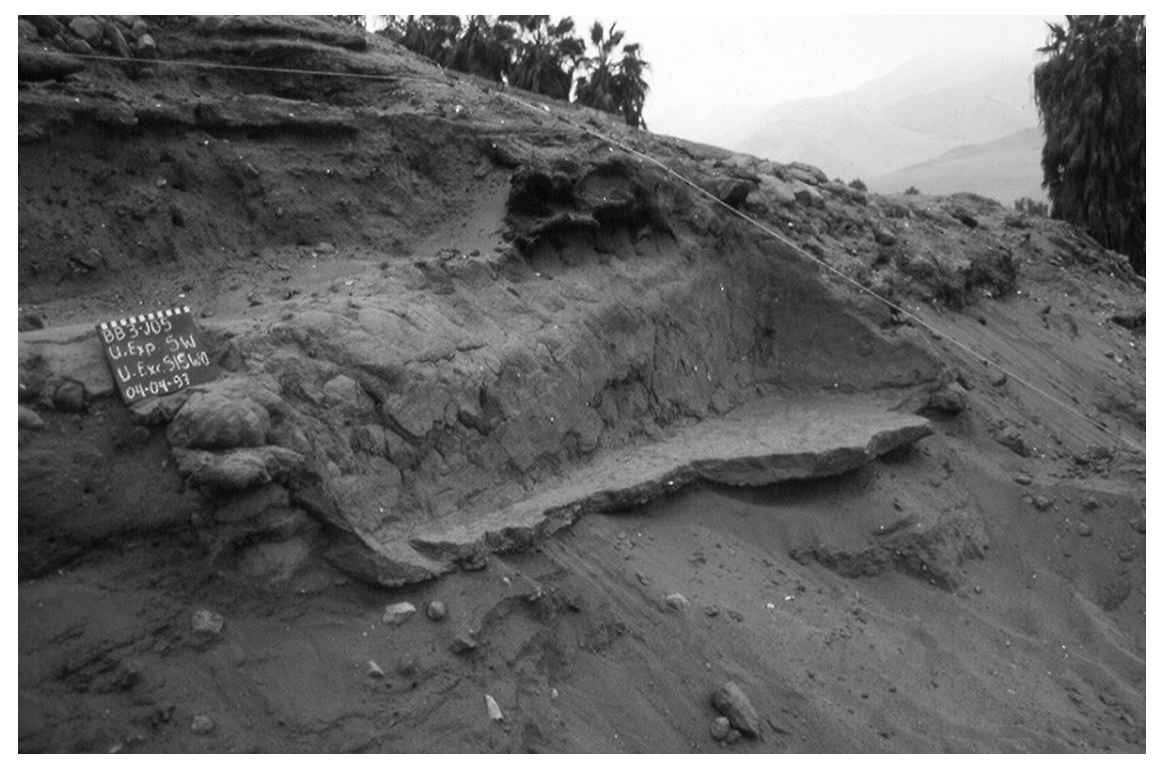

Fig. 25 - Depósito de maíz al sur, en el perfil oeste.

Mac Neish, Patterson y Browman (1975) muestran un panorama más amplio y definen un área de interrelación entre los valles de Chilca y Chillón. Estos autores caracterizan el lapso entre 250 y $50 \mathrm{aC}$. como un período de predominio de poblaciones pescadoras, que coexisten con asentamientos fortificados en la cima de los cerros lo cual evidenciaría una época de enfrentamientos por los recursos. Esto se confirma en Miramar donde se hallaron terrazas para secar pescado y pequeñas plataformas de carácter público. En los valles de Rímac y Lurín, además, tenemos aldeas dispersas en la parte baja, mientras que en el valle medio se situaban en los declives de los cerros mirando hacia el mar. Estos asentamientos se asociaban a pequeñas pirámides hechas de adobes cónicos. Dichos adobes, suponemos, podrían tratarse de adobes plano-convexos.

Baños de Boza tuvo economía sustentada en recursos tanto marítimos como agrícolas. Así pues, uno de los hallazgos en el perfil oeste fue una pequeña habitación construida en adobes planos-convexos y paredes enlucidas, parcialmente destruido (Fig. 25), asignada a la fase constructiva 4. De su interior se recuperó una cantidad considerable de restos de maíz, lo cual nos sugiere el uso de esta habitación como depósito. Al mismo tiempo, durante las excavaciones, se recuperaron restos malacológicos como Thais Chocolata, Aulacomia Ater, Choromitylus Chorus, Mesodesma Donacium, por citar los más frecuentes. Los restos de pescado no eran menos abundantes. Debemos mencionar, además, el aprovechamiento del junco que se desarrolla en las lagunas próximas al sitio. En los niveles superiores, durante la limpieza de los alrededores del pozo de Willey, se hallaron grandes restos de estas fibras que habrían servido de techumbre.

A partir de la información estratigráfica en Cerro Trinidad, Playa Grande y Baños de Boza podemos plantear que el Blanco sobre Rojo es contemporáneo con Lima hasta sus fases 3-4, según el esquema de Patterson. A falta de una tipología precisa en 
las investigaciones anteriores que haría necesario revisar los materiales, es difícil correlacionar los rasgos de ambos estilos. Sin embargo, en la última fase de Baños de Boza podemos vislumbrar algunos rasgos Lima como platos carenados y tazas, coetáneos con Blanco sobre Rojo según puede verse en nuestra fase 4.

Algunos elementos propios del Blanco sobre Rojo perduraron hasta una época bastante avanzada del estilo Lima. Asílo observamos en la cerámica del sitio PV44-14GO7 del valle de Chancay (Ravines,1995). Según la cronología de Patterson, pertenecerían a las fases 4-6 (5-7 según Ravines) de Lima. Dentro de los tipos formales podemos encontrar platos hondos similares a los de Baños de Boza, los cuales hemos definido como tipos II 5 y I 3 (Córdova, 1999). Otros platos menos profundos tienen decoración interna Lima pero con la cara externa engobada de blanco, como acontece en las piezas Blanco sobre Rojo. Incluso observamos un plato con líneas blancas internas agrupadas en cinco, típicas de la fase 2 de Baños de Boza (Córdova, 1999: lam 9:1).

La ausencia de cerámica Lima en Baños de Boza se puede deber a que el sitio mantuvo autonomía estilística y política, aún durante la ocupación Lima en el valle. Es posible que las poblaciones Lima hayan "respetado" el área de Baños de Boza, considerando su función como sitio ceremonial y buscando otras zonas del valle para asentarse. A la fecha, falta un mayor estudio especialmente sobre el patrón de asentamiento poniendo énfasis en estructuras domésticas lo cual, sin duda, brindará un mejor panorama sobre la situación socio política del valle de Chancay durante la época Blanco sobre Rojo .

\section{Agradecimientos}

La realización de esta investigación no habría sido posible sin el apoyo constante de maestros y amigos a quienes quiero manifestar mi más profundo agradecimiento. A mi asesor de tesis, el doctor Krzisztoff Makowski, por su invalorable apoyo durante las investigaciones; a Iván Amaro por sus valiosos consejos durante el análisis de gabinete. Igualmente, al Lic. Hernán Carrillo cuya experiencia en el campo fue de vital importancia para la buena culminación de las excavaciones. A la Fundación Museo Amano, cuyo apoyo material permitió llevar adelante los trabajos de excavación. Igualmente a la familia Marticorena, propietaria del terreno donde se encuentra el sitio de Baños de Boza. Finalmente, quiero agradecer a todas aquellas personas quienes de diversas maneras me apoyaron; a la Dra. Mercedes Cárdenas y la señorita Danila Vega del Instituto Riva-Agüero, al personal del Proyecto arqueológico-Taller de Campo Tablada de Lurín, a Benjamín Guerrero y Celia Díaz quienes realizaron el levantamiento topográfico del sitio; a Gabriel Ramón, Luis Cáceres, Vicente Cortéz, Gabriel Rimachi, César Astuhuamán, y Flora Ugaz, por su apoyo en el manejo de programas de computadora.

\section{Referencias citadas}

AGURTO CALVO, S. \& SANDOVAL, S., 1974 - Inventario, Catastro y Delimitación Del Patrimonio Arqueológico del valle del río Chancay; Lima: Ms.

BENNETT, W., 1944 - The North Highlands of Peru. Excavations in the Callejón de Huaylas and Chavín de Huantar. Anthropological papers of the American Museum of Natural History. Vol. 31. Part 1: 114 p.; New York. 
CÁRDENAS, M., 1980 - Tablada de Lurín. Informe general de los trabajos 1958-1980, 194p.; Lima: Pontificia Universidad Catolica del Perú. Seminario de Arqueología del Instituto Riva Agüero.

CÁRDENAS, M., 1999 - Tablada de Lurín: Excavaciones 1958-1989. Tomo I: 426p.; Lima: Pontificia Universidad Católica del Perú.

CÓRDOVA, H., 1999 - Baños de Boza: Cronología y Estilo de la Tradición Blanco sobre Rojo. Tesis de Licenciatura; Lima: Pontificia Universidad Católica del Perú, 70 p., 64 lams., 46 fotos.

DELGADO, M., 1992 - Investigaciones en Villa el Salvador. Pachacamac. Revista del Museo de la Nación. Agosto, Vol. 1, No 1: 135-136; Lima.

EARLE, T., 1972 - Lurin Valley, Peru: Early Intermediate Period Settlement Development. American Antiquity, Vol 37, No 4: 467-477.

KROEBER, A., 1926 - The Uhle Pottery Collections from Chancay, Vol. XXI (7): 265-304; Berkeley: University of California Publications in American Archaeology and Ethnology.

LANNING, E., 1963 - An Early Pottery Collection from Ancón, Central Coast of Peru. Ñawpa Pacha, No 1: 47-60; Berkeley.

LUMBRERAS, L. G., 1970 - Los Templos de Chavín, 165p.; Lima: Museo de Arqueología y Etnología de la U.N.M.S.M. - Corporación Peruana del Santa.

MACNEISH, R., PATTERSON, T. \& BROWMAN, D., 1975 - The Central Peruvian prehistoric interacción sphere, 97p.; Massachusetts: Papers of the Robert S. Peabody Foundation for Archaeology - Phillips Academy-Andover,

MAKOWSKI, K. \& CORNEJO, M., 1993 - Informe de las excavaciones en Tablada de Lurín 1991-1993. In: Willay. Newsletter of Andean Anthropological Research Group. 39/40. Winter 1992/Spring 1993. Peabody Museum, Harvard University. Cambridge. Ma 02138, U.S.A.

MALDONADO, A., 1943 - Las Lagunas de Boza, Chilca y Huacachina y los gramadales de la costa del Perú, 143p.; Reimpreso de "Actas y trabajos del Segundo Congreso Peruano de Química"; Lima.

MONTOYA URIARTE, H., 1995 - Análisis de fragmentería cerámica excavada en un relleno de clausura. Complejo Arqueológico "Huaca Pucllana", Vol. 1: 233p.; Lima. Tesis para optar el título de Licenciado en Arqueología. Pontificia Universidad Católica del Perú.

ORTON, C., TYERS, P. \& VINCE, A., 1993 - Pottery in Archaeology. 269p.; Cambridge: Cambridge University Press.

PALACIOS, J., 1987-1988 - La secuencia de la cerámica temprana del valle del Rímac en Huachipa. Gaceta Arqueológica Andina, No 16: 13-34; Lima: INDEA.

PATTERSON, T., 1966 - Pattern and Process in the Early Intermediate Period pottery of the central coast of Peru, 180p.; Berkeley: University of California Publications in Anthropology 3.

PATTERSON, T. \& LANNING, E., 1964 - Changing settlement pattern of the central peruvian coast. Ñawpa Pacha, No 2: 113-123; Berkeley.

PATTERSON, T., MC CARTHY, J. P. \& DUNN, R., 1982 - Polities in the Lurín Valley, Peru, during the Early Intermediate Period. Ñawpa Pacha, No 20: 61-82; Berkeley.

RAVINES, R., 1995 - La cerámica del sitio PV44-14GO7, valle de Chancay, Lima. Boletín de Lima, No 100: 57-76; Lima.

ROSTWOROWSKI DE DIEZ CANSECO, M., 1981 - Recursos Naturales Renovables y Pesca en los siglos XVI y XVII, 180p.; Lima: Instituto de Estudios Peruanos.

SHADY, R. \& RUÍZ ESTRADA, A., 1978 - Huaura-costa central, interacción regional en el Período Intermedio Temprano. Arqueológicas, No 18: 1-99; Lima: Museo Nacional de Arqueología y Antropología del Perú.

SILVA, J. \& GARCÍA, R., 1997 - Huachipa-Jicamarca: cronología y desarrollo sociopolítico en el Rímac. Boletín del Instituto Francés de Estudios Andinos, 26(2): 195-228; Lima: Instituto Francés de Estudios Andinos. 
STOTHERT, K. \& RAVINES, R., 1977 - Investigaciones Arqueológicas en Villa el Salvador. Revista del Museo Nacional. No 43: 157-225; Lima.

TABÍO, E., 1957 - Excavaciones en Playa Grande, costa central del Perú, 1955. Arqueológicas, 1(1): 2-42; Lima: Museo Nacional de Arqueología y Antropología del Perú.

TABÍO, E., - Excavaciones en la costa central del Perú. 180p.; La Habana: Academia del Departamento de Antropología - Academia de Ciencias de la República de Cuba.

WILLEY, G., 1943 - Excavations in the Chancay Valley. Archaeological Studies in Peru, 19411942, 222p.; New York: Columbia University Press.

WILLEY, G., 1953 - A functional analysis of "horizon styles". Peruvian Archaelogy, (4): 8-15; Menasha: Wendell Bennett comp. Memoirs of the Society of American Archaeology. 